\title{
The aggregate implications of changes in the labour force composition*
}

\author{
Alessandro Mennuni \\ University of Southampton \\ alessandro.mennuni@soton.ac.uk
}

April 10, 2019

\begin{abstract}
Labour composition by gender, age, and education has undergone dramatic changes over the last half century in the United States. Furthermore, the volatility of total market hours differs systematically between genders, age, and education groups. I develop a large scale business cycle model where these demographic patterns and their transitional dynamics are taken into account and find that demographic change accounts for $30 \%$ of the observed changes in aggregate volatility over this period of time. Additionally, these demographic changes are responsible for a significant fraction of the GDP growth observed in the considered period of time.
\end{abstract}

\section{JEL Classification Codes: E32, J11, J22}

Keywords: Demographic transition, Business cycle, GDP growth

*I thank my advisor Martin Gervais for invaluable guidance. I also thank the editor, the reviewers, and seminar participants at the the NBER 2012 SI "Consumption", European University Institute, the Nordic Summer Symposium, EEA/ESEM 2011, RES annual conference 2012, U. of Edinburgh, Uppsala, Universitat de Barcelona, Autonoma de Barcelona, Birmingham, La Sapienza, the workshop on dynamic macroeconomics in Vigo, the Vienna Macro Café, the workshop on macroeconomic dynamics in Bologna. I also thank Árpád Ábrahám, Jerome Adda, Juan Carlos Conesa, Russell Cooper, Corrado Giulietti, Nils Gottfries, John Hassler, Jonathan Heathcote, John Knowles, Per Krusell, Sarolta Laczó, Yang Lu, Ramon Marimon, Xavier Mateos-Planas, Andrea Moro, Salvador Ortigueira, Xavier Raurich, Morten Ravn, Victor Rios-Rull, Alice Schoonbroodt, Kjetil Storesletten, Roman Sustek, Michele Tertilt, Arnau Valleredes-Esteban, Thijs van Rens, Ludo Visschers, and especially Paul Klein for helpful comments. The usual disclaimer applies. 


\section{Introduction}

This paper studies the role demographic change by gender, age, and education played in the prolonged period of business cycle volatility slowdown and fast economic growth that preceded the Great Recession.

In an influential paper, Jaimovich and Siu (2009) (J-S) found that changes in the age composition of the labour force had a large and significant effect on aggregate volatility during the postwar period. ${ }^{1}$ Meanwhile, labour composition changes by gender and education have been equally dramatic: Katz and Autor (1999) and Katz and Freeman (1994) among others documented the well known increase in female labour supply and in the number of workers with high education. Importantly, these patterns are correlated with the increase in prime-aged population. Furthermore, changes by gender and education have the potential to affect aggregate fluctuations because total hours worked by women are less volatile than those by men, and college educated hours are less volatile than those of lower educated workers. This is a similar fact to the one that motivated the work of J-S; that the volatility of the time series of total hours worked by prime age workers is lower than that of the young and older workers.

The evidence above, and in particular the fact that these variables are correlated, motivates the study of the implications of all these demographic changes jointly: studying them in isolation may induce an omitted variable bias. However, to add gender and education factors as possible driving forces of business cycle volatility is challenging because of endogeneity problems. The regression analysis developed by J-S exploits the fact that changes in the age-distribution of the population, determined by birth rates lagged at least 15 years, are exogenous to changes in current economic activity. Unfortunately, it is not easy to find equally persuasive instruments for the labour composition by education, and especially gender. This is important because, as this paper documents, while transitions by age and education consisted primarily of changes in population shares (mainly due to the post-War baby boom and to increasing educational attainments), changes by gender are about the number of women in employment and hours per worker. Unlike the population distribution, these more intensive margins are choice variables. That notwithstanding, it is instructive to start with a panel

\footnotetext{
${ }^{1}$ The finding is robust to considering a larger pool of countries (Lugauer and Redmond 2012), or exploiting the variation in demographic change across the United States (Lugauer 2012b). Lugauer (2012a) reconciles the result with a search and matching model. Janiak and Monteiro (2016) find that differences in tax rates explain some of the differences in aggregate volatility across countries through their effects on the age distribution of labour.
} 
regression analysis on US states following (Lugauer 2012b), but also including gender and education regressors as well as the one by age. Even without establishing causality, regressing output volatility on these demographic factors finds that where there is more female labour supply, more people with high education, or lower young age population, there is lower business cycle volatility. These results are encouraging: while the causality is still unclear, they clarify that not only across time but also across US states there is a correlation between business cycle volatility and the labour composition by gender and education, as well as by age. ${ }^{2}$

J-S complement their analysis by constructing a simple accounting exercise to measure the contribution of these demographic changes to the Great Moderation, the large volatility decline that started in the 1980s as initially documented by Kim and Nelson (1999) and McConnell and Perez-Quiros (2000). To isolate the effect due purely to the change in composition, they construct a counterfactual series for aggregate employment, where the population shares by group are held constant. It would be interesting to apply a similar exercise here. One issue is that, as mentioned, while compositional changes by age and education are mainly about the population margins, changes by gender are due to the more intensive margins of labour participation, employment, and individual hours. Since these margins account for essentially all business cycle volatility in aggregate employment and hours, it is not revealing to hold them constant because that way one would remove all the business cycle. One ideally needs to construct some counterfactual time series that retain all the variation that these margins would have had without demographic change. To this aim one needs to decompose the movements that are due to demographic change from those that would have occurred otherwise. This is done here through a model.

The framework is a business cycle model with overlapping generations similar to Ríos-Rull (1996) in which I introduce heterogeneity by gender and education. The demographic changes are driven by exogenous trends in birth rates, in the share of newborns with low and high education, and in the time spent in non market activities for men and women. This way, consistently with the data, changes by gender are due

\footnotetext{
${ }^{2}$ To dig further into the aforementioned endogeneity issues I instrument the age population with lagged birth as J-S and Lugauer (2012b). I also instrument the variables by gender and education with their one year lag, or with 5 year lags. The sign of the coefficients do not change and in particular the gender and education regressors remain strongly significant. However, a test for weak identification suggests that the instruments are only strong when the gender and education factors are instrumented with one lag. Unfortunately, one lag only does not entirely exclude the possibility of reverse causality.
} 
to labour supply, while those by age and education involve the population margin. ${ }^{3}$

Changes in the labour composition have the potential to affect aggregate volatility mainly for two reasons. One, purely mechanical, is that different groups have different volatility. A second reason is that the sensitivity of each group to the business cycle evolves with the group size. As an example of how demographic change affects the response of labour by group to business cycle shocks, Goldin (2006) argues that female labour supply elasticity declines as the commitment to work of women increases. This indirect effect might have non negligible implications for aggregate volatility because the paper documents large changes in the volatility by group over time that could be a consequence of demographic change. Thus, it is desirable that the model predicts how demographic change affects the group-specific response to business cycle shocks.

In the model, differences in the volatility of labour by group can arise from factors related to labour supply and factors related to labour demand. The model takes an explicit stand on how the labour supply elasticity and thereby the sensitivity of market hours is affected by the various demographic changes. This relationship is consistent with the empirical evidence. In particular, the evidence suggests a utility function that makes labour supply elasticity a declining function of labour input. This way the model is consistent with the prediction of Goldin (2006) that labour supply elasticity declines as the commitment to work increases. With this specification the model matches the empirical correlations between the evolution of hours volatility at a disaggregated level and the demographic changes. So presumably the model correctly predicts how hours volatility would have evolved in a counterfactual world without demographic change. To model labour demand by group I adopt a flexible production function which, in addition to conventional Total Factor Productivity (TFP) shocks, allows for shocks to specific labor input by age, sex, and education. These group specific labour demand shocks generate changes in the wage gaps which in turn explain some of the changes in the labour composition and some of the business cycle volatility.

A computational challenge arises from the fact that the demographic distribution is

\footnotetext{
${ }^{3}$ A previous version — Mennuni (2013) — had education as a choice variable. The positive trend in educational attainments was partly due to an increasing wage premium and partly to a declining cost of education. This choice played a negligible role for the results. Intuitively what matters in this paper is that cyclical volatility differs among education groups but education decisions did not explain that. The only way the education decision was endogenous to aggregate volatility was in the extent to which the decision to pursue education depends on current business cycle conditions; but in each period this decision only pertains the newborn cohort. This had negligible aggregate effects as for all other cohorts in the labour force, education was a state variable. However, other mechanisms through which education might affect aggregate volatility are conceivable, see Lugauer (2012c).
} 
not constant and the model is solved over a large transition; this makes linearization methods around the steady state - the methodology used by Ríos-Rull (1996) and the typical technique used to solve large scale stochastic models - inaccurate. To address this issue, the model is solved with a new technique which consists of applying linearization methods at many points over the equilibrium path. The solution is more accurate than that found with standard linearization methods only aronud the steady state and it is described in detail, and in a way that is applicable to a large class of models, in Mennuni and Stepanchuk (2016).

The model is used to measure the contribution that the labour compositional changes played on aggregate volatility. A counterfactual simulation where the exogenous trends are such that the labour composition fluctuates around its steady-state levels finds that output volatility would have been much lower in the period characterized by high volatility that preceded the Great Moderation (1967-1984), and slightly more volatile in the Great Moderation period when there was little volatility (1985-2007). By accounting for part of the high volatility in the first sub-sample and the slowdown in the 1980s, labour reallocation accounts for $31 \%$ of the Great Moderation. ${ }^{4}$ Trends in gender, and especially education, are found to be more important than previously thought: trends in education play the most important role, followed by age and sex, in the change in output volatility. Furthermore, these results suggest that other things equal, business cycle volatility should be expected to increase somewhat in the next decades due to the ongoing ageing of the population and the fact that the counterbalancing transition by gender and education is largely completed. ${ }^{5}$

With this model I can also measure the contribution to growth of this demographic transition. Growth in the model comes from the productivity shocks (TFP and labour specific), initial assets below steady state, and because of demographic change. Intuitively, the increase in female labour, and in the share of relatively more productive and hard working prime age and highly educated workers, contributed to the growth

\footnotetext{
${ }^{4}$ Between the first and second subsample, output volatility decreased by $41.9 \%$ in the baseline simulation with demographic change. In the counterfactual simulation (where the labour composition is trendless) the moderation is only of $28.9 \%$, so these demographic trends account for (41.9-28.9)/41.9 or $31 \%$ of the moderation in output volatility.

${ }^{5}$ But to be clear, while demographic trends explain part of business cycle volatility, this is of limited help to predict recessions such as the financial crisis: the labour composition can affect the propagation of shocks, but the severity of a recession depends fundamentally on the size of the shock. In fact, baseline and counterfactual volatility are roughly the same in the last part of the sample (2008-2013). Intuitively, the demographic trends have largely converged, so there is not much difference in the two scenarios for the last period of time.
} 
observed in the past half century. Comparing the baseline simulation and those without demographic change, I find that $16 \%$ of the average output growth between 1967 and 2013 is due to sex trends, $9 \%$ to trends in age and $17 \%$ is due to education trends. Finally, taken together these trends account for a staggering $39 \%$ of the average output growth. It should be noted that this exercise is different from a growth accounting exercise where the growth of each input is assumed independent from the others. For instance, capital accumulation is determined by the endogenous savings of each demographic group. Furthermore, part of the labour composition is endogenous through labour supply. However, a limitation is that the long run trends in the population by age, educational attainment, and in non market hours are exogenous. In practice it is likely that these trends are jointly determined with GDP growth, especially labour participation and educational attainment. ${ }^{6}$ Thus the results pertaining to growth should be taken as a first pass where the role of demographics may be overstated. Yet these numbers are conservative when compared to the literature which offers estimates for each of these dimensions taken individually. ${ }^{7}$ These findings suggest that the slow growth observed in recent years is likely to persist given that the demographic trends have largely converged. Thus this evidence supports the "secular stagnation" hypothesis formulated by Hansen (1939) and recently evoked by Summers (2013) among others.

The paper proceeds as follows. Section 2 documents facts and contains the reduced form exercises. Sections 3 and 4 set up and calibrate the model. Section 5 tests the model and measures the effects of labour reallocation. Section 6 concludes. Appendixes $\mathrm{A}$ and $\mathrm{B}$ define the model equilibrium and include results on the production function.

\section{Stylized facts and reduced form exercises}

As it is well known, aggregate output volatility in the U.S. increased during the early 1970s and declined during the 80s and 90s. ${ }^{8}$ Recently, volatility has increased again and there is renewed curiosity about its future unfolding. To relate these facts to the

\footnotetext{
${ }^{6}$ Another limitation is that while the model distinguishes between population and labour per capita, the employment over population, and hours per worker margins, are not disentangled.

${ }^{7}$ For instance Greenwood et al. (2005) find that the rise in female labour accounts for about $19 \%$ of growth between 1900 and 1980. Feyrer (2007) finds that age labour composition changes predict almost 12\% of GDP growth between 1990 and 1995. The number found here for education is slightly higher than the $15 \%$ found by Goldin and Katz (2008) for human capital: they argue that their number is likely to be an understatement.

${ }^{8}$ See Kim and Nelson (1999), McConnell and Perez-Quiros (2000) and Stock and Watson (2003).
} 
labour force composition, following Gomme et al. (2005) and J-S, I use data from the March supplement of the CPS to construct annual series of labour data, downloaded from the Integrated Public Use Microdata Series (King et al. (2010), cps.ipums.org).

\section{$2.1 \quad$ Total hours}

Figure 1 shows the share of paid hours worked over time by gender, age (young (15-29), prime age (30-59) and older workers) and low and high education (at least four years of college). These are shares of total hours per capita by group, i.e. hours per worker times number of workers in a group divided by the total number of hours worked by the entire working population. ${ }^{9}$
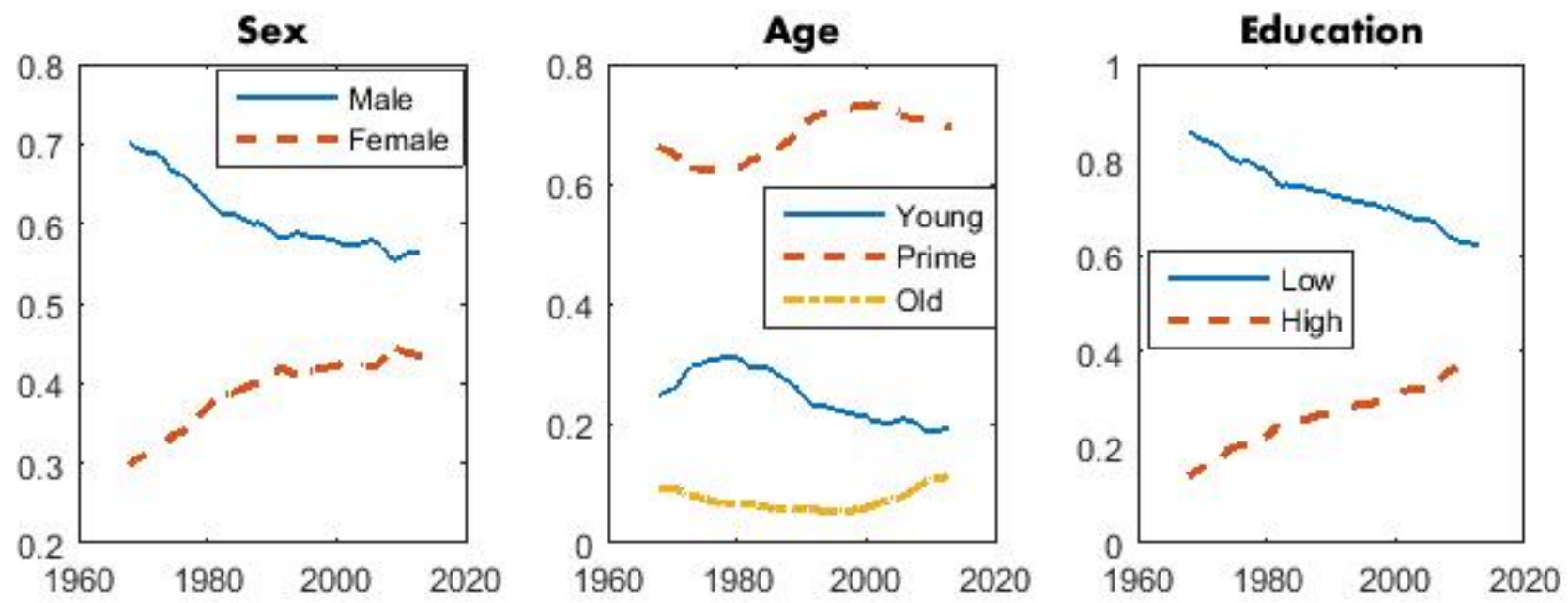

Figure 1: Share of hours by gender, age and education

Notes: young workers range from 15 to 29 years old. Prime age workers range from 30 to 55 . The old are those 56 and above. By high education is meant at least four years of college.

As is reported in the first two columns of Table 1, the share of hours worked by prime age workers increased relative to those by other age groups, moving from an average of $64 \%$ prior to 1984 to an average of $71 \%$ from $1985 .{ }^{10}$ By contrast, the share of hours by the young and old fell. Furthermore, the volatility of hours is substantially lower for prime age workers as initially documented by Clark and Summers (1981). This is

\footnotetext{
${ }^{9}$ Aggregates for market hours are constructed by including individuals of at least 15 years old who reported their gender and education level and declared they worked a positive amount of weeks and for a positive wage.

${ }^{10} 1984$ is the reference year adopted by the literature as the beginning of the Great Moderation. See for instance Stock and Watson (2003)
} 
shown in column 3, where the standard deviation of the filtered time series of hours by age for the entire sample (1967-2013) is reported. ${ }^{11}$

Table 1: Hours by gender, age and education

\begin{tabular}{lcccc}
\hline & Share of hours 67-84 & Share of hours 85-13 & St. dev & $\frac{\text { St.dev(85-07) }}{\text { St.dev }(67-84)}$ \\
\hline \hline Young & 28.99 & Age & \\
Prime age & 63.50 & 22.19 & 2.61 & 81.23 \\
Old & 7.51 & 70.70 & 1.49 & 55.17 \\
\hline \multicolumn{5}{c}{ Gender } \\
Women & 34.28 & 41.99 & 1.79 & 97.09 \\
Men & 65.72 & 58.01 & 1.31 & 59.01 \\
\hline Low & 79.99 & Education & & 66.87 \\
High & 20.01 & 69.00 & 2.02 & 57.17 \\
\hline
\end{tabular}

Notes: numbers are expressed in percentage terms. Share of hours is the ratio of hours by each group to total hours. The data contain information on weekly hours and weeks of work in a year. There are two variables for weeks of work: one starting in 1976 that contains the number of weeks for each respondent. Another, which goes back to the beginning of the sample, classifies weeks between 1 and 6. The latter is used. Since both measures exist from 1976, bins 1 to 6 are converted into weeks by taking the average number of weeks of workers in each bin.

The relative increase in prime-age hours and the fact that hours are less volatile for this age group may have contributed to the reduction in aggregate volatility. These two facts also hold by gender and education. As shown in Table 1, between the first and second sub-sample hours worked by women increased relative to those by men. It is less well known, however, that male hours are more volatile than female hours: the standard deviation of hours is $1.31 \%$ for women and $1.98 \%$ for men. ${ }^{12}$ Similarly, from the last two rows, the share of the highly educated increased and their hours volatility

\footnotetext{
${ }^{11}$ Like J-S, to isolate business cycle frequencies I use the Hodrick-Prescott (HP) filter on logged data with a smoothing parameter of 6.25 as suggested by Ravn and Uhlig (2002). Results are robust to using a parameter of 10. Jaimovich et al. (2013) find that these results are also robust to detrending with the band-pass filter. In a previous version, I used growth rates rather than the HP-filter throughout the paper and reached the same conclusions.

${ }^{12}$ This fact has also been recognized by Gomme et al. (2005) and J-S; Abraham and Shimer (2001) and more recently Hoynes et al. (2012) report a similar fact for unemployment by gender. The fact is all the more surprising given that at the individual level, labour income for women is more volatile than for men. Evidently, some of the volatility at the female individual level is idiosyncratic and washes out in the aggregate. Doepke and Tertilt (2016) elaborates on this further.
} 
is lower than that of the less educated.

To summarize, by sex and education as well as age, there has been an increase in the hours worked by the groups with lower volatility. These are the basic facts behind the conjecture that these trends matter for aggregate volatility changes.

Next total hours are decomposed in population, labour participation, employment, and hours margins. This finer cut highlights the following: while transitions by age and education mainly involve population shares, the transition by gender involves the more intensive margins of participation, employment, and hours per individual.

\subsection{Population, labour force participation, employment and hours}

Table 2 shows population shares by gender, age and education. The population includes all individuals that are at least 15 years old. Columns one and two show that population changes are large by age and education, but minor by sex. For instance, the stable prime age population increased from 45.9 to $51.3 \%$ of the total while the volatile young decreased from 34.5 to $27.6 \%$. Similarly, the population with high education showed a remarkable increase from 12 to $22 \%$. Instead, sex ratios remained roughly constant. However, labour composition by sex has been characterized by a strong transition in labour participation and in employment over population rates reported in tables 3 and 4 respectively; for instance, employment over population for women moved from an average of $43 \%$ in the first sample to $54 \%$ in the second sample. Labour participation and employment have also changed for the other groups as reported in the Table, but to a smaller degree.

Similar changes also characterized hours per worker, or per labour force participant, reported in tables 5 and $6 .{ }^{13}$ These hours increased significantly more for women than for men but they are roughly unchanged by age and education groups.

The third column in Tables 4 and 6 highlights that volatilities at these more intensive margins are consistent with total hours (Table 1): for employment over population and hours (per workers or per labour force participant) the standard deviations for women, prime age and the highly educated are lower than for their respective counterparts (males, other age groups and workers with lower education). Interestingly, this is not

\footnotetext{
${ }^{13}$ Variables are constructed taking care of the fact that the March CPS data on earnings and hours refer to the year preceding the interview while population and employment refers to the interview date.
} 
Table 2: Population shares by gender, age and education

\begin{tabular}{|c|c|c|c|c|}
\hline & population shares $67-84$ & population shares $85-13$ & St. dev & $\frac{\operatorname{St.dev}(85-07)}{\operatorname{St.dev}(67-84)}$ \\
\hline & \multicolumn{4}{|c|}{ Gender } \\
\hline Women & 52.40 & 51.78 & 0.09 & 88.35 \\
\hline \multirow[t]{2}{*}{ Men } & 47.60 & 48.22 & 0.10 & 85.97 \\
\hline & \multicolumn{4}{|c|}{ Age } \\
\hline Young & 34.51 & 27.63 & 0.44 & 146.74 \\
\hline Prime age & 45.86 & 51.26 & 0.21 & 59.10 \\
\hline \multirow[t]{2}{*}{ Old } & 19.63 & 21.12 & 0.39 & 193.26 \\
\hline & \multicolumn{4}{|c|}{ Education } \\
\hline Low & 87.78 & 78.40 & 0.18 & 115.88 \\
\hline High & 12.22 & 21.60 & 0.83 & 74.40 \\
\hline
\end{tabular}

Table 3: Labour force participation by gender, age and education

\begin{tabular}{|c|c|c|c|c|}
\hline & Participation $67-84$ & Participation 85-13 & St. dev & $\frac{\operatorname{St.dev}(85-07)}{\operatorname{St.dev}(67-84)}$ \\
\hline \multicolumn{5}{|c|}{ Gender } \\
\hline Women & 46.55 & 57.40 & 0.53 & 67.47 \\
\hline Men & 74.65 & 71.67 & 0.37 & 98.93 \\
\hline \multicolumn{5}{|c|}{ Age } \\
\hline Young & 61.89 & 64.78 & 0.78 & 92.24 \\
\hline Prime age & 73.52 & 80.77 & 0.28 & 79.56 \\
\hline Old & 24.70 & 23.15 & 1.15 & 116.50 \\
\hline \multicolumn{5}{|c|}{ Education } \\
\hline Low & 57.34 & 60.14 & 0.45 & 70.71 \\
\hline High & 78.37 & 79.46 & 0.32 & 87.63 \\
\hline
\end{tabular}

the case for the labour participation by gender: in this case the standard deviation for women is higher than that for men and so the lower volatility of female total hours relative to those by males is all accounted for by a lower volatility of female hours per labour force participant. Furthermore, the labour force participation margin shows small fluctuations. For example, the standard deviation of the labour force participation of women is $0.53 \%$. This is about half the standard deviation of employment over population for women.

In summary, while transitions by age and education mainly involve population shares, the one by sex involves the intensive margins of female labour force participation, 
Table 4: Employment over population by gender, age and education

\begin{tabular}{lcccc}
\hline & Empl / pop 67-84 & Empl / pop 85-13 & St. dev & $\frac{\text { St.dev(85-07) }}{\text { St.dev (67-84) }}$ \\
\hline \hline Women & \multicolumn{5}{c}{ Gender } \\
Men & 43.21 & 54.07 & 1.07 & 56.74 \\
\hline & 70.95 & 67.38 & 1.34 & 66.23 \\
\hline Young & 55.92 & Age & \\
Prime age & 70.76 & 58.55 & 1.90 & 65.97 \\
Old & 23.75 & 77.11 & 0.92 & 62.47 \\
\hline & & 22.20 & 1.28 & 95.77 \\
\hline Low & 53.42 & Education & & \\
High & 77.74 & 55.76 & 1.40 & 91.18 \\
\hline
\end{tabular}

Table 5: Hours per labour force participant by gender, age and education

\begin{tabular}{lcccc}
\hline & hours $67-84$ & hours $85-13$ & St. dev & $\frac{\text { St.dev }(85-07)}{\text { St.dev }(67-84)}$ \\
\hline \hline Women & \multicolumn{5}{c}{ Gender } & \\
Men & 25.2 & 28.3 & 1.33 & 58.0 \\
\hline & 33.2 & 33.6 & 1.94 & 66.3 \\
\hline Young & 24.37 & Age & & 68.88 \\
Prime age & 33.81 & 24.73 & 2.43 & 60.01 \\
Old & 27.72 & 34.20 & 1.50 & 109.04 \\
\hline & 28.54 & 2.02 & 54.47 \\
Low & Education & & 95.25 \\
High & 28.52 & 29.29 & 2.00 & 1.30 \\
\hline
\end{tabular}

Notes: numbers are percentage terms.

employment and hours. Furthermore, the difference in the volatilities by group is mainly accounted for by the individual hours and the employment margins.

\section{$2.3 \quad$ Regression analysis}

So far this analysis has looked at the time series variation in the US. Instead J-S and Lugauer (2012b), using panel data techniques, get identification from the time series variation plus cross sectional variation. It would be telling to adopt a panel data approach and include gender and education variables. The problem is that unlike vari- 
Table 6: Hours per worker by gender, age and education

\begin{tabular}{lcccc}
\hline & hours 67-84 & hours 85-13 & St. dev & $\frac{\text { St.dev(85-07) }}{\text { St.dev (67-84) }}$ \\
\hline \hline Women & Gender & \\
Men & 27.1 & 30.0 & 1.29 & 50.4 \\
\hline & 34.9 & 35.8 & 1.78 & 56.1 \\
\hline Young & Age & & 61.98 \\
Prime age & 26.92 & 27.37 & 2.26 & 49.11 \\
Old & 35.12 & 35.82 & 1.41 & 108.70 \\
\hline & 28.84 & 29.74 & 1.94 & 46.50 \\
Low & 30.59 & Education & & 93.42 \\
\hline High & 37.79 & 31.60 & 1.86 & 1.23 \\
\hline
\end{tabular}

Notes: numbers are percentage terms.

ables by age, which these authors have successfully instrumented with lagged births, education and especially gender variables cannot be considered fully exogenous to economic activity. That notwithstanding, it is instructive to run a panel data analysis: even without establishing causality, it is interesting to see whether states with more female labour supply and education have less business cycle volatility. This is possible because the CPS data can be broken down by US state. To this aim I regress business cycle volatility on the labour force share of females and the population share with high education, as well as the population share in young age:

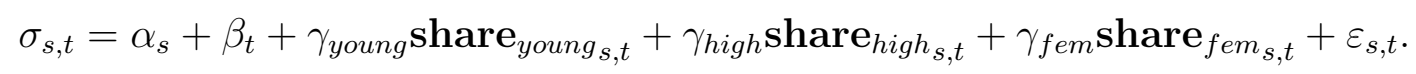

Following Lugauer (2012b), share young $_{\text {is }}$ the youth share of the population and $\sigma$ measures for each US state $s$ the nine year rolling window of the output deviations from trend centred at year $t .{ }^{14}$ Output volatility is constructed using GDP per capita by US state deflated with state price deflators available from 1977 from the Bureau of Economic Analysis. Vectors $\alpha$ and $\beta$ represent US states and time dummies respectively. The time dummy captures a possible common time trend that characterizes output volatility as well as the demographic variables. This helps to avoid the coefficients just capturing a spurious correlation. ${ }^{15}$ In addition to the variables above, which are the

\footnotetext{
${ }^{14}$ This is the typical approach used in the literature to measure output volatility. J-S and Iseringghausen and Vierke (2018) demonstrate robustness to alternative methods, filters and time windows.

${ }^{15}$ See also Iseringghausen and Vierke (2018) who find that the results in J-S are robust to further accounts of the possible non-stationarity of the data.
} 


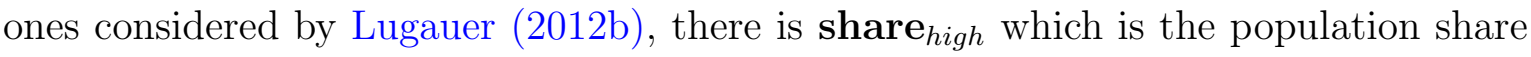
with high education and share ${ }_{f e m}$, which is the labour force participation of women over the total labour force. ${ }^{16}$

The results are reported in Table 7 . In the first column are the raw OLS coefficients which have the sign expected and are statistically significant with standard errors robust to autocorrelation and heteroscedasticity. This shows that where there is more female labour supply, more people with high education, or lower young age population, there is lower business cycle volatility. In the next columns the young age population is instrumented by the sum of births between 29 and 15 years prior to each time $t{ }^{17}$ The variables by gender and education are instrumented with a lag, or with 5 lags. The sign of the coefficients does not change and in particular gender and education remain strongly significant. However, with 5 lags the weak identification F-test gives a low value suggesting weak instruments.

Table 7: Regression estimates

\begin{tabular}{lccc}
\hline \hline & $(1)$ & $(2)$ & $(3)$ \\
\hline & OLS & 2SLS 1 Lag & 2SLS 5 Lags \\
\cline { 2 - 4 }$\gamma_{\text {fem }}$ & -0.020 & -0.060 & -0.223 \\
$p$-values & $(0.005)$ & $(0.001)$ & $(0.005)$ \\
$\gamma_{\text {young }}$ & 0.150 & 0.322 & 0.278 \\
$p$-values & $(0.000)$ & $(0.034)$ & $(0.133)$ \\
$\gamma_{h i g h}$ & -0.040 & -0.066 & -0.094 \\
$p$-values & $(0.022)$ & $(0.000)$ & $(0.005)$ \\
State fixed effects & yes & yes & yes \\
Time dummies & yes & yes & yes \\
$F$-stat first stage & & 12.953 & 6.12 \\
$N$ & 1666 & 1666 & 1666 \\
\hline
\end{tabular}

Note: this table reports estimates for the regression in Equation (1) with standard errors robust to autocorrelation and heteroskedasticity. The variables and data are defined in the text. All regressions include a full set of state and time-effect dummies for each year (1982-2013). F-stat first stage indicates the Cragg-Donald Wald F statistic for weak identification.

\footnotetext{
${ }^{16}$ I used the population margin for age and education because, as shown earlier, demographic trends by age and education are mainly about the population margin while those by gender are about the intensive margins. Among the intensive margins by sex, I chose labour participation because it is the least volatile and thus it is more palatable to think of it as exogenous to business cycle volatility.

${ }^{17}$ Births data for each state are available on scanned documents (one for each year), published by the National Office for Vital Statistics.
} 
While the causality may still be unclear from this panel regression alone, this analysis clarifies that not only across time but also across US states there is a correlation between aggregate volatility and the labour composition by gender and education, as well as by age. The inability to fully convince about the exogeneity of labour changes by gender and education motivates the more structural analysis.

\subsection{Reduced-form accounting exercises}

J-S complement their regression analysis with a simple exercise to account for the Great Moderation. Let aggregate employment per capita at time $t$ be $E_{t}=\sum_{i} e_{i, t} p o p_{i, t}$ where $e_{i, t}$ is employment over population in group $i$ and $p o p_{i, t}$ is the population in group $i$ divided by total population. Similarly, it is also possible to construct counterfactuals for aggregate hours $H_{t}=\sum_{i} h_{i, t}$ pr $_{i, t}$ pop $p_{i, t}$ where $h_{i, t}$ is hours per labour force participant and $p r_{i, t}$ is the participation rate of the population included in group $i$.

J-S consider experiments in which they hold the population constant and then compare the volatility before and during the Great Moderation for both the baseline and the counterfactual data. Specifically, they set $\widehat{p o p}_{i, t}$ by age constant at the average values during the pre-moderation period (1967-1984) and account for $20 \%$ of the moderation in total hours. Holding population shares by education constant accounts for $10 \%$. A similar experiment would not be interesting by gender because, as documented earlier, the population composition by gender is essentially unchanged. However they report that holding the gender composition of the workforce constant at the premoderation levels resulted in essentially no change in the volatility of aggregate hours.

A problem with holding the workforce constant, i.e. setting $p r_{i, t}$, or $h_{i, t} p r_{i, t}$ constant, is that these are the margins that vary the most over the business cycle while population shares show little short run variation. It follows that so constructed counterfactual variables do not capture enough of the business cycle movements and, as such, are not informative as to how business cycle volatility has changed over time. It is worth stressing that the issue is especially severe for the gender composition where all the action involves the intensive margins. But for the main exercise considered by J-S (of holding the age population constant) the issue is not so relevant because, apart perhaps from migration issues, population shares have negligible business cycle volatility. So holding population shares constant seems reasonable because it isolates the volatility of the other margins which are the ones that vary over the business cycle. However, the methodology of holding margins constant does not extend so easily to margins that 
have a long run trend, but also vary at the business cycle frequency.

One needs a way to keep the business cycle fluctuations of the volatile margins, but remove their long run trends. In principle it would be possible to identify long run trends for each group without a model by regressing each margin over time trends. However, it would be difficult to give an economic interpretation to this identification. Furthermore, these demographic changes are not entirely independent from one another. For instance: how much of the labour composition changes by education would have happened, had the female labour participation not increased? How much did the increasing presence of young female workers affect the age composition of the labour force? The model takes more meaningful and testable stands. For instance, demographic change by age and education will come from taking seriously the overlapping generations structure of the model and the data on birth rates and college graduation.

Furthermore, as J-S acknowledge, the accounting exercise above may lead to biased results because it implicitly assumes that the volatility of group-specific market work is not affected by demographic change: in the baseline and and in counterfactuals group-specific hours fluctuate in the same way. Without an a priori view, this seems a reasonable starting benchmark: it helps isolate the purely mechanical role played by changing the demographic composition. But it raises an important question: is the group-specific response to business cycle shocks affected by demographic composition and would this change the results?

Tables 1-6 last column document substantial changes in volatility within each group in all the margins considered: if these changes were an indirect consequence of these demographic trends, their implications for aggregate volatility should be attributed to demographics. For instance, there is evidence that labour supply elasticities declined over time, especially for females (Heim 2007 and Blau and Kahn 2007); as advocated by Goldin (2006), this elasticity decline may be related to the increase in employment and hours per worker by almost all groups and especially by females (Tables 4 and 6-first and second column). Empirically, the higher labour supply, the lower its elasticity. E.g. males versus females, prime age versus closer to retirement, women without children versus women with children; see Reichling and Whalen (2012). A causal link between labour supply and its elasticity implies that the mentioned increases in hours and participation played a further role on aggregate volatility by inducing the moderation within each group. Indeed, between the first and second sample, the ratio of the standard deviation of HP-filtered hours per worker or employment, and that of hourly 
wages, declined for all the groups. This is consistent with a lower sensitivity to shocks, possibly endogenous to labour demographics.

In the model, labor supply elasticity responds endogenously to changes in the labour composition. The importance of this channel in explaining aggregate volatility has also been argued recently by Doepke and Tertilt (2016). However, it should be noted that also the volatility of hourly wages moderated for most groups. For instance, the standard deviation of HP-filtered female hourly wages between 1985 and 2007 is $80 \%$ that between 1967 and 1984. This suggests that not all the moderation in hours should be attributed to a diminished sensitivity to shocks, but possibly also to smaller shocks, or good luck. Through the model, aggregate and groups specific shocks are identified, so the possibility that smaller shocks explain the moderation is also taken into account.

\section{The model}

In each period, the economy is populated by a continuum of individuals and an equal random number $p_{0}$ of males and females are born. A share $q^{m} \in(0,1)$ of new born males and $q^{f} \in(0,1)$ of new born females have high education.

\subsection{The problem of the agents}

Agents are distinguished by their sex $g=\{f, m\}$ for female or male; age $j \in\{1, J\}$; education $e=\{h, l\}$ for high or low; and their assets $a$. Each agent chooses consumption $c$, assets $a^{\prime}$, and market hours $\ell$, to solve the following problem:

$$
V(g, j, e, a ; \omega)=\max _{c, \ell, a^{\prime}} \ln (c)+\chi \frac{(1-\ell-\tilde{h})^{1-\sigma}}{1-\sigma}+\beta \zeta_{j} E\left[V\left(g, j+1, e, a^{\prime} ; \omega^{\prime}\right)\right]
$$

subject to the constraints: $\zeta_{j} a^{\prime}+c=a(1+r)+w(g, j, e) \ell$,

$$
a^{\prime} \geq 0 \text { if } j=J, \quad c \geq 0, \quad \ell \in[0,1-\tilde{h}],
$$

where $V$ defines expected utility discounted at factor $\beta \in[0,1]$ times $\zeta_{j} \in[0,1]$, the survival factor for the agent at age $j$; it is such that people die for sure at age $J$, i.e. $\zeta_{J}=0{ }^{18} \sigma$ regulates the Frisch elasticity of labour supply. Like in neoclassical settings, $\chi$ is a scaling factor that helps match hours targets as detailed in Section 4 . As explained in Section 5.2.3, this utility specification makes the labour supply elasticity

\footnotetext{
${ }^{18} \zeta_{j}$ in the budget constraint reflects competitive annuity markets, see Ríos-Rull (1996).
} 
a function of labour input; this helps match the declining sensitivity of labour supply discussed in Section 2.4. $\tilde{h}$ is an exogenous time cost specific to each gender and education. ${ }^{19}$ Parameter indexation will be made explicit whenever necessary to avoid confusion; for example $\tilde{h}_{g, e}$.

$r$ is the interest rate; $w(g, j, e)$ the wage, specific to each sex, age, and education. The period utility after death is assumed equal to 0 , hence $V(g, J+1, e, a ; \omega)=0$ and the zero debt constraint in the last period of life at age $J$ which ensures that agents do not run Ponzi schemes. The expectation $E$ is taken rationally over $\omega^{\prime}$ given $\omega$, the vector containing the aggregate state variables as explained below. Agents are born with zero assets. $^{20}$

\subsection{Demographic distribution}

Denote $p:\{f, m\} \times\{1, \ldots, J\} \times\{h, l\} \rightarrow \Re_{+}$last period mass of agents by sex, age and education. $p^{\prime}(g, 1, h)=p_{0} q^{g}$ and $p^{\prime}(g, 1, l)=p_{0}\left(1-q^{g}\right)$ are the masses of newly born with high and low education respectively, with $g=f, m$. Let the mass of older households be defined recursively as $p^{\prime}(g, j+1, e)=p(g, j, e) \zeta_{j}$ for $j=\{1, J-1\}$.

\subsection{Firms}

Competitive firms maximize profits using the following production function

$$
y=A^{1 / \theta}\left(\alpha k^{\theta}+(1-\alpha) L^{\theta}\right)^{1 / \theta},
$$

where $A$ is total factor productivity (TFP), $\alpha$ is associated with the labour share of total output and $\theta$ measures the complementarity across capital and $L$, which is a composite of several labour groups:

$$
L=\left(\sum_{i=1}^{I}\left(z_{i} n_{i}\right)\right) .
$$

\footnotetext{
${ }^{19}$ In the absence of a more sophisticated theory of the household, the evolution of this parameter helps reproduce the distribution of hours by gender. Its reduction over time captures housework technology improvements and a fall in child care cost which, jointly with the reducing gender wage gap, causes increases in female market hours. See Greenwood et al. (2005) and Attanasio et al. (2008).

${ }^{20}$ In a previous version (Mennuni 2013), individuals of opposite gender were matched stochastically based on their educational level as in Heathcote et al. (2010). Education was also an endogenous choice. These two features had negligible effects on the results. Intuitively, the education decision is not that much affected by business cycle shocks because agents enter the labour market after the decision to educate. Furthermore, the return from education is spread over many years and thus only marginally affected by the business cycle conditions at the time of making the education choice.
} 
$z_{i} \mathrm{~S}$ are labour-augmenting technology shocks specific to each labour group; $n_{i}$ is hours worked by all individuals categorized in group $i$.

$z_{i}$ s capture sectorial shocks and other aspects of the production process not explicitly modeled, which move relative demands of labour inputs.

There is a mapping between firm groups $i$ and agents: each group $i$ is formed of agents of the same gender, age group and education level. ${ }^{21}$ The mapping is represented by I dummy matrixes $\psi_{i}(g, j, e)$ which contain zeros and ones depending on whether the labour input of the agent belongs to group $i$. So, for instance, group 1 is formed of women, young and with low education. For a generical $i$,

$$
n_{i}=\sum_{g} \sum_{j=1}^{J} \sum_{e} \ell(g, j, e, a ; \omega) p^{\prime}(g, j, e) \psi_{i}(g, j, e),
$$

where $\ell(g, j, e, a ; \omega)$ is the labour input of each agent in that group. ${ }^{22}$ The number of groups $I$ is 12, i.e. the 2 genders times the 3 age groups times the 2 education levels.

The representative firm hires labour according to the following condition

$$
(1-\alpha) A^{1 / \theta}\left(\alpha k^{\theta}+(1-\alpha) L^{\theta}\right)^{1 / \theta-1} L^{\theta-1} z_{i}=w_{i}
$$

for every $i$, where $w_{i}$ is the wage rate for group $i$; so if $\psi_{i}(g, j, e)=1$, then $w(g, j, e)=$ $w_{i}$. Capital is demanded according to the following condition

$$
\alpha A^{1 / \theta}\left(\alpha k^{\theta}+(1-\alpha) L^{\theta}\right)^{1 / \theta-1} k^{\theta-1}=r+\delta
$$

where $\delta$ is the depreciation rate of capital.

The advantage of the adopted constant elasticity of substitution specification relative to a Cobb-Douglas (CD) is that with the latter, output and the marginal productivities of labour and capital move proportionally. Therefore it is in general not possible to match aggregate production given the inputs, while matching hours and wages through labour demand. Instead, with a CES with $\theta \neq 0$, it is possible, say, to increase output by increasing the productivity of capital but not that of labour, or viceversa. This is because while output, labour and capital demand move proportionally with $A^{1 / \theta}$, they are not affected proportionally by $z$. Instead with a CD, it is impossible to disentangle

\footnotetext{
${ }^{21}$ Consistently with Section 2, there are three age groups: the young (1-10), the prime age (11-35) and the older agents (36-40).

${ }^{22}$ Since there are no idiosyncratic shocks within the groups, all agents of the same gender, age and education have the same asset levels, hence there is no integration over $a$ in Equation (6).
} 
labour augmenting and TFP shocks. ${ }^{23}$ This is important given that I wish to match the output time series as well as hours and wages. ${ }^{24}$

\subsection{State space}

To make rational choices, agents need to know their type (gender, age and education) and asset position $a$. They also need to predict prices, which depend on the shocks and on the distribution of assets and agents across age, gender and education. The state space is defined in more detail next.

\subsubsection{Exogenous processes}

Let the logarithm of the labour productivity processes $z_{i}$, the logarithm of the TFP process $A$ and the logarithm of the mass of new born $p_{0}$ be AR1 stochastic processes. Furthermore, the education shares $q^{g}$ and housework $\tilde{h}_{g, e}$ with $g=\{f, m\}$ and $e=$ $\{h, l\}$ are deterministic processes with an AR1 structure. ${ }^{25}$ Let these variables be collected in the vector $G=\left[A, Z, p_{0}, q^{g}, \tilde{h}_{g, e}\right]$, where $Z$ is the vector of all $z_{i}$.

\subsubsection{Aggregate state}

The remaining dimensions of the state space, denoted $\omega$ in Value Function (2), contain aggregate state variables that affect households' decisions through prices and expectations: the shocks, the distribution of agents by sex, age and education $p$, and assets across all groups of agents $a_{1}, \ldots, a_{m}$, where $m=J \times 2 \times 2$, i.e the $J$ generations alive, the 2 genders and the 2 education groups. The distribution of assets is a finite dimensional vector because there are no idiosyncratic shocks among people of the same age, gender and education. So $\omega=\left[G, p, a_{1}, \ldots, a_{m}\right]$. Let $\Pi\left(\omega^{\prime} \mid \omega\right)$ be the transition density for $\omega$ implied by the the exogenous processes $G$ and the laws of motion for assets and the demographic distribution $p$. Appendix A reports the equilibrium definition.

\footnotetext{
${ }^{23}$ To see this, consider the following CD: $y=A k^{\alpha}(z \ell)^{(1-\alpha)}$. Let $\ell$ be homogeneous labour. The marginal productivities for labour and capital are $(1-\alpha) A k^{\alpha-1}(z \ell)^{-\alpha} z$ and $\alpha A k^{\alpha-1}(z \ell)^{(1-\alpha)}$. It is clear that output, labour and capital demand are all proportional to $A z^{(1-\alpha)}$. Then it is not possible to increase output without increasing both labour and capital demand. This proportionality is also reflected in the fact that the capital and the labour share of income are constant and makes output and wages strongly pro-cyclical in RBC models, giving rise to the employment productivity puzzle.

${ }^{24} \mathrm{~A}$ previous version also considered imperfect substitutability between labour inputs but the estimation of the complementarity was very close to the case of perfect substitution considered here.

${ }^{25}$ Starting with initial values away from their steady states, these two variables will help make trends in hours by gender and education behave as in the data.
} 


\section{Calibration}

The model period is a year and parameter values are reported in Tables 8 and 9 .

Table 8: Summary of parametrization

\begin{tabular}{cccc}
\hline Parameter & Meaning & Moment to Match & Value \\
\hline \hline$\beta$ & discount factor & interest rate & 0.99 \\
$\delta$ & capital depreciation & capital-output ratio & 0.06 \\
$\sigma$ & curvature of leisure & hours volatility & See Table 10 \\
$\chi$ & scaling utility of leisure & hours levels & See Table 10 \\
$\zeta_{j}$ & survival rates & vital statistics & see text \\
$\rho_{p_{0}}, \gamma_{p_{0}}, \sigma_{p_{0}}$ & birth rates process & share of 20-year-olds & $0.92,0.002,0.0014$ \\
$\rho_{h}^{m}, \gamma_{h}^{m}$ & education share process & male education composition & $0.91,0.026$ \\
$\rho_{h}^{m}, \gamma_{h}^{m}$ & education share process & female education composition & $0.91,0.032$ \\
$\rho_{\tilde{h}}$ & housework persistence & evolution of female market hours & 0.97 \\
$\alpha$ & prod. share parameter & labour share & 0.43 \\
$\theta$ & prod. elasticity parameter & capital-labour complementarity & -0.25 \\
\hline
\end{tabular}

Table 9: Productivity processes

\begin{tabular}{cccccccccccccc}
\hline & $\mathrm{m}, \mathrm{y}, \mathrm{l}$ & $\mathrm{m}, \mathrm{y}, \mathrm{h}$ & $\mathrm{f}, \mathrm{y}, \mathrm{l}$ & $\mathrm{f}, \mathrm{y}, \mathrm{h}$ & $\mathrm{m}, \mathrm{p}, \mathrm{l}$ & $\mathrm{m}, \mathrm{p}, \mathrm{h}$ & $\mathrm{f}, \mathrm{p}, \mathrm{l}$ & $\mathrm{f}, \mathrm{p}, \mathrm{h}$ & $\mathrm{m}, \mathrm{o}, \mathrm{l}$ & $\mathrm{m}, \mathrm{o}, \mathrm{h}$ & $\mathrm{f}, \mathrm{o}, \mathrm{l}$ & $\mathrm{f}, \mathrm{o}, \mathrm{h}$ & $A$ \\
\hline \hline$\rho$ & .87 & .86 & .88 & .88 & .89 & .88 & .90 & .89 & .89 & .91 & .90 & .88 & .91 \\
$\gamma$ & .17 & .24 & .13 & .19 & .19 & .25 & .14 & .20 & .18 & .18 & .13 & .21 & 0 \\
$100 \sigma(u)^{2}$ & 3.19 & 3.17 & 3.17 & 3.01 & 3.17 & 3.05 & 3.13 & 2.86 & 3.61 & 3.20 & 3.53 & 3.45 & .09 \\
\hline
\end{tabular}

\subsection{Production, depreciation and discount factor}

$\theta$ governs the elasticity of substitution in the production function. It is set to -0.25 in accordance with the literature that suggests more complementarity than the CD case. See for instance Leon-Ledesma et al. (2010) and Choi and Ríos-Rull (2009).

$\alpha$ is set to match the average labour and capital share of output: in the model, the capital share is $A \alpha\left(\frac{k}{y}\right)^{\theta}$, so it also depends $A$ and on $\frac{k}{y}$. $A$ is normalized to be one 
on average. ${ }^{26}$ In turn $\frac{k}{y}$ depends on discount factor $\beta$ and on capital depreciation $\delta$. I set $\beta=0.99$ and $\delta=0.06$. With these values, in steady state $\frac{k}{y}=2.9$. This gives $\alpha=0.43$. These parameters also imply a steady state net interest rate of $4.7 \%$ and a saving rate of $18 \%$.

The time series for $A$ and $z_{i}$ are jointly identified through the production function and labour demands (Equations (4)-(7)) given the raw data for output, factor inputs and wages. These equations are simultaneous but conceptually, the time series for $A$ is backed out as a Solow residual, and those for $z_{i}$ from the labour demand equations similarly, for instance, to Katz and Murphy (1992). With these time series in hand, I estimate the following AR1 process for each $z_{i}$ and for $A$ by by Ordinary Least Squares:

$$
\log \left(z_{i, t}\right)=\gamma_{i}+\rho_{i} \log \left(z_{i, t-1}\right)+u_{i, t},
$$

where $u_{i, t}$ are the shock innovations. The $\mathrm{AR} 1$ process for $\log (A)$ is:

$$
\log \left(A_{t}\right)=\rho_{a} \log \left(A_{t-1}\right)+u_{a, t}
$$

Time trends in Equations (9) and (10) were not significant and therefore omitted. ${ }^{27}$

Parameters for the productivity processes are summarized in Table 9.

\subsection{Preferences}

Table 10 reports utility parameters $\sigma, \chi$, the hours targets, and the implied elasticities by group. Next I describe how these parameters are set.

\section{Hours targets by group}

The vector $\chi$ is such that the steady state matches the hours distribution by sex, age and education reported in Table 10. This distribution is based on the average hours per capita by gender, age and education between 2000 and 2007, but with a caveat. In the model, workers of each age can either be of high or low education. Therefore, life starts at age 22, after college. However, Jaimovich et al. (2013) found that workers between

\footnotetext{
${ }^{26}$ The average level of $A$ can be normalized because for any level of $A$, it is possible to find a value of $\alpha$ and the shocks $z_{i}$ such that output is preserved, as well as the marginal productivity of capital and of labour in each group. Since $\alpha$ is a constant, changes in $A$ and $z_{i}$ are identified independently of the normalization on the average level of $A$.

${ }^{27}$ Figure 3 shows the identified time series, the initial trends depend on the processes starting below steady state. As discussed in Section 4.5, this model accounts for much of the growth in the raw data through transitional dynamics, not through steady growth in productivity. So the model variables in levels eventually converge (very slowly given the demographic trends) to a steady state with no need to remove a balanced growth path.
} 
Table 10: Hours targets and utility parameters

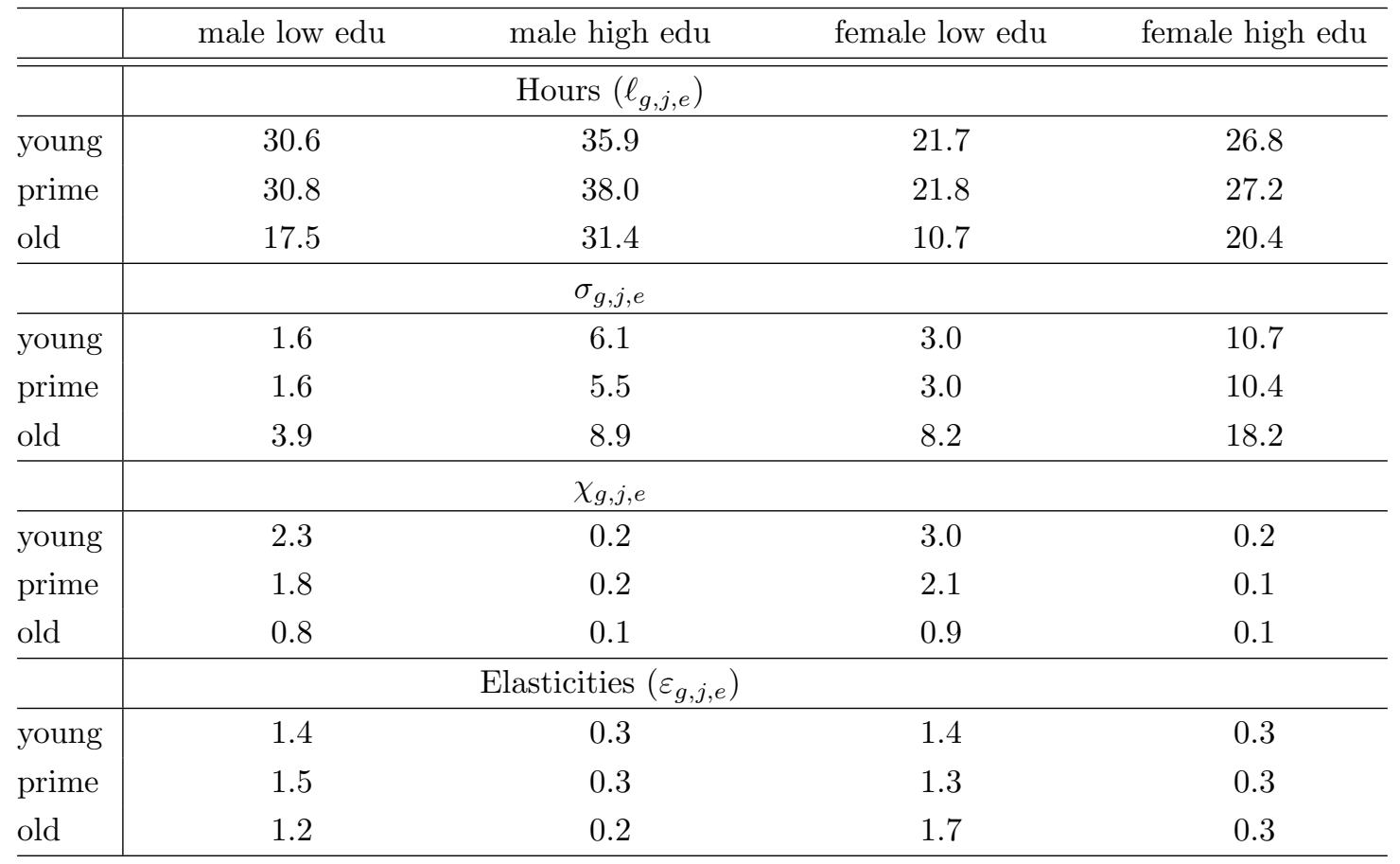

Note: $\chi$ vary for each age $j$, so they are averages across all ages in the age bracket.

15 and 19 account for a non negligible share of total hours volatility. Missing their hours share could reduce the contribution of age demographics to aggregate volatility. To avoid this, I impute to young workers (from age 22 to 29) the hours share of workers from 15 to 29. This way, hours by age groups are consistent with Section 2, where the young go from age 15 to 29. Since workers from 15 to 21 work a small number of hours, this does not majorly change the properties of labour supply over the life cycle. For instance, labour supply is hump shaped as it can be appreciated by Table 10, first 3 rows. Furthermore, this disproportion in the hours per worker of the young does not affect Frisch elasticities of labour supply as $\sigma$ is age-group specific and is calibrated taking this into account.

It should also be noted that since the model does not have an employment margin, to construct hours, I multiply hours per worker by the share of people working. For instance, for prime male workers with high education, the average time spent working by those who work between 2000 and 2007 is $41.1 \%$ of their time (time is defined as $15 \mathrm{~h}$ a day times 365 ). The working-population rate is $92.4 \%$. So steady state hours for prime age workers with high education is 0.411 times 0.924 , or $38 \%$. 


\section{Labour supply elasticities}

With the utility function specified in Equation (2), The Frisch elasticity of labour supply for a generic individual (e.g. a woman, with high education and a given age) is

$$
\varepsilon \equiv \frac{\partial \ell}{\partial w} \frac{w}{\ell} \mid \lambda=\frac{1}{\sigma} \frac{(1-\ell-\tilde{h})}{\ell},
$$

where $\lambda$ is the lagrange multiplier on her budget constraint. ${ }^{28}$

$\sigma$ is group specific. It satisfies four criteria. First, I calibrate it to have equal average Frisch elasticities of labour for men and women over the simulation. ${ }^{29}$ Second, I restrict $\sigma$ to have equal average Frisch elasticities between young, prime age, and older workers. ${ }^{30}$ Third, I let Frisch elasticities of the highly educated be lower than that of the less educated to match the ratio between the volatilities of total market hours by education. ${ }^{31}$ Finally, $\sigma$ implies an average elasticity over the simulation equal to 1.1. This number lies within the range of micro estimates for women and it is also within the estimates for men, yet above the mean (which is 0.85 in the studies surveyed by Keane (2011)), but it is much lower than macro calibrations. ${ }^{32}$

It is useful to discuss some implications of the resulting labour supply elasticities.

${ }^{28}$ The first order condition for labour of a generic individual is

$$
\chi(1-\ell-\tilde{h})^{-\sigma}=\lambda w .
$$

Differentiating this last condition with respect to $w$, but holding $\lambda_{i}$ constant, one gets

$$
\frac{\partial \ell}{\partial w} \frac{w}{\ell}=\frac{\lambda}{\chi \sigma}(1-\ell-\tilde{h})^{1+\sigma} \frac{w}{\ell} .
$$

substituting out $\frac{w}{\ell}$ in the left-hand side from (12) one gets Equation (11).

${ }^{29}$ These are the averages of the Frisch elasticities for each representative agent in a given group, weighted by their mass. For instance, at each time $t$, the elasticity of male workers is $\frac{\sum_{j=1}^{J}\left(1 / \sigma_{m, j, h}\left(1-\ell_{t}(j, m, h)-\tilde{h}_{m, h, t}\right) / \ell_{t}(j, m, h)\right) p_{t}(m, j, h)+1 / \sigma_{m, j, l}\left(\left(1-\ell_{t}(j, m, l)-\tilde{h}_{m, l, t}\right) / \ell_{t}(j, m, l)\right) p_{t}(m, j, l)}{\sum_{j=1}^{J}\left(p_{t}(m, j, h)+p_{t}(m, j, l)\right)}$. These statistics are computed period by period in the simulation, then their averages over the time is taken.

${ }^{30}$ The elasticity is assumed not to differ by age in accordance to Jaimovich et al. (2013) who argue that the U-shaped volatility of hours as a function of age is due to age specific sensitivity of labour demand, not labour supply.

${ }^{31}$ As discussed below, that elasticities are education specific may reflect unmodeled labour contracts, matching frictions, and non market opportunities specific to types of worker. They could also be due to genuine differences in the characteristics of the population, which correlates with educational choices.

${ }^{32}$ The business cycle literature typically chooses a high level of Frisch elasticities in order to have sufficient aggregate hours volatility, which tends to be lower than that found in the data. The lower level here makes the elasticity in Equation (11) more sensitive to changes in $l$, which helps match trends in hours volatility. See Ljungqvist and Sargent (2011), Prescott et al. (2009) and Erosa et al. (2015) among others for a discussion of how extensive margins can be incorporated into a life cycle model to reconcile micro and macro labour supply elasticities. 
The model qualitatively matches the fact that female total hours are less volatile than that of males even though men and women have the same labour Frisch elasticities; the ratio of the standard deviations of filtered hours worked by women over that of men is 0.66 in the data and 0.83 in the model.

The model also matches the fact that prime age hours are less volatile than those of the young and the old even though labour Frisch elasticities are not age specific: the standard deviation of filtered total hours of prime workers over that of the more volatile young and older workers is 0.70 in the data and 0.51 in the model simulations. This result supports the findings of Jaimovich et al. (2013) that the U-shaped age volatility of labour is not due to differences in labour supply elasticity, but to demand factors: they micro-found labour demand differences through a production function that exhibits experience-skill complementarity similarly to Krusell et al. (2000) and Castro and Coen-Pirani (2008). It is not obvious how to extend that function to the case of several labour groups with different complementarities. So here age specific labour demand differences are due to productivity shocks specific to each group identified through the data as explained below. The variance of labour productivity shocks by age implies less volatile wages for prime age workers, which is also true in the data. ${ }^{33}$

While the model naturally matches the relative volatility by sex and age without having sex or age specific Frisch elasticity, this is not the case for education. The average elasticity of workers with low education is 1.33, that for workers with high education is 0.26 . The reason why these elasticities by education must differ is that while hours of workers with higher education are less volatile than those of the lower educated, the opposite is true for wages: wages are more volatile for workers with high education. This pattern has also been documented in an online appendix by Jaimovich et al. (2013). Within a neoclassical setting where the labour supplied is always a choice, it is necessary to impose lower labour supply elasticity for workers with higher education to match the relative volatility of hours and wages at the same time. Indeed, according to Keane (2011), it is plausible that education is related to tastes for work and Blau and Kahn (2007) estimate that labour supply elasticity is lower for women with higher education. Becker and Mulligan (1997) argue that education has explanatory power on preferences and even that education might change preferences. While this model does not explain why elasticities differ, Section 5.2.3 shows that the model predicts the

\footnotetext{
${ }^{33}$ If anything, the model generates a too pronounced U-shaped volatility as a function of age. As explained below, sensitivity analysis suggests this has a negligible role for how business cycle volatility has evolved over time.
} 
evolution of relative hours and wage volatilities over time.

\subsection{Survival probabilities}

Survival probabilities $\zeta_{j}$ for $j=\{1, \ldots, J\}$ come from the National Center for Health statistics Vital statistics of the US, $1992 .{ }^{34}$ Since this paper focuses on active workers, attention is restricted to people from age 22 to 65 . Therefore, no one can live for more than 44 periods and $\zeta_{44}=0$. This is counterfactual, and it could affect the labour supply decision over the life-cycle. In particular the absence of retirement implies a counterfactual wealth distribution (agents die with zero assets) and it has implications for the response to shocks. A retirement decision could further increase the volatility of older workers, see Prescott et al. (2009). However, even without retirement, the model generates too much volatility of hours by the older workers. Furthermore, non reported sensitivity analysis suggests that the Frisch elasticity of old workers has negligible effects on how business cycle volatility has evolved. Intuitively, this is because the share of hours of the old is smaller and more stable over the sample than that of young and prime workers as shown in Figure 1. ${ }^{35}$

\subsection{Trends in the composition of labour}

Demographic trends by age, education, and gender are driven by the processes for the number of new born, the share of newborn men and women with high education, and non market work.

The number of new born $p_{0}$ is modeled as an exogenous AR1 process with constant $\gamma_{p_{0}}$, persistence $\rho_{p_{0}}$, and variance $\sigma_{p_{0}}^{2}$, all reported in Table 8 . This quite simplistic way to model birth generates variable fertility that matches changes in the labour distribution by age; see Ríos-Rull (2001) for a discussion of alternative fertility regimes.

$\tilde{h}_{g, e}$ is zero for men and it starts positive and converges to zero for women. The initial level and persistence of the deterministic AR1 process for female housework is calibrated to replicate trends in the labour composition by sex. Its initial level of 0.14 accounts for $52 \%$ of the average total (home and market work) working time for women. The gradual decay of this variable "liberates women from the home" and increases their market labour supply and educational incentives. See Greenwood et al. (2005).

\footnotetext{
${ }^{34}$ Vol II, sec. 6 life tables page 13, Washington: Public Health Service. 1996.

${ }^{35}$ This could change in the future given the general increase in life expectancy.
} 
$q^{m}$ and $q^{f}$; the newborn men and women with high education, are modeled as deterministic AR1 processes with parameters $\gamma_{g, e}^{q}$ and $\rho_{g, e}^{q}$ reported in Table 8. Their steady state levels are such that the model matches the share of the highly educated by gender between the young in the period 1999-2007, which is $q^{f}=0.36, q^{m}=0.29$. Initial conditions are 0.13 for men and 0.08 for women and persistence are picked to replicate trends in the labour composition by education. Since there are no shocks affecting housework and $q^{m}$ and $q^{f}$, agents have perfect foresight on these trends.

\subsection{Initial conditions}

As mentioned, initial conditions for home production, the size of the new generation, education shares are picked to match gender, age, and education trends. Initial values for the productivity parameters are identified through the estimation of the production function. The initial population distribution reflects the initial distribution in the data.

It remains to pin down the assets' distribution. I first take the values that solve the model for a steady state assuming that the other initial conditions were stationary. ${ }^{36}$ Asset levels so determined seem a bit large: when I simulate the model over the transition with these initial conditions, agents disinvest in the first few periods. The intuition for this is that the initial conditions for gender, age and education trends imply future growth, a positive wealth effect relative to the assumption of no growth implicit in the initial steady state; therefore agents respond by reducing investment. Therefore, I put initial assets to $85 \%$ of those in the initial steady state. There is no initial disinvestment of capital, but the business cycle statistics are qualitatively unchanged. Furthermore, with these initial conditions, the initial capital-output ratio is of 2.9 , which is very close to the empirical counterpart. Importantly, the average growth rate of output over the simulation is quite close to the empirical one for output over population in working age: $1.53 \%$ in the model and $1.60 \%$ in the data. ${ }^{37}$ This is striking because the model does not have exogenous productivity growth: according to this model, virtually all the growth we observed in the last 5 decades is due to the transition from initial conditions. Furthermore, this is only partly due to the fact that initial assets and productivity shocks are below the final steady state, inducing a grow-

\footnotetext{
${ }^{36}$ This is a convenient way to pick initial assets, but to hold the initial demographic distribution stationary is inconsistent with general equilibrium. Sensitivity analysis is discussed in Section 5.3.4.

${ }^{37}$ The comparison with output over population in working age is more appropriate than the usual output per capita as the model only includes agents in working age. Output over population in working age is constructed through income data from the CPS.
} 
ing transition. ${ }^{38}$ The counterfactual exercises ran in Section 5.3 show that important factors for the observed growth are that women increased their labour supply and that there are more prime age and highly educated workers.

\section{Model-based quantitative analysis}

\subsection{Computation}

The computation of this model is challenging because the state space is quite large: 890 variables, of which 365 are state variables. Large DSGE models can be handled by perturbation methods around the steady state. ${ }^{39}$ This method is reasonably accurate when simulations remain close to the deterministic steady state. This is not the case here because the model is simulated from starting conditions which are quite far from the steady state. To resolve this, a new methodology is developed which essentially consists of applying repeated local approximations over the entire transition path, between the initial conditions and the steady state. ${ }^{40}$

The algorithm is detailed in Mennuni and Stepanchuk (2016); a brief summary of its logic is given here. The goal is to find the equilibrium path given initial conditions for the state vector, called $x_{0}$, and time series for the shocks (the actual time series of shocks is known to the computer programmer, but is unknown to the agents in the model). First, an auxiliary path from $x_{0}$ to the steady state is drawn through the policy functions obtained by perturbation around the steady state. Then, new perturbations are computed backward along this path: from the proximity to the steady state back to the initial conditions. The policies approximated at the initial conditions are used to compute the next point. Then, the algorithm iterates treating the new point as an initial condition and the iterations end when the initial conditions coincide with the final period of the time series of the shocks.

\footnotetext{
${ }^{38}$ For instance, if initial assets are $95 \%$ of those in the initial steady state, the initial capital-output ratio is 3.2 and output grows at an average of $1.50 \%$.

${ }^{39}$ See Ríos-Rull (1996) for an application of linear quadratic methods in a model that shares a similar OLG structure to the one in this paper.

${ }^{40} \mathrm{By}$ limiting the local approximations to the transition path, the number of grid points does not increase with the number of state variables.
} 


\subsection{Assessing the model}

The experiments for which the model has been built are reported in Section 5.3. Before that, some checks are performed to get a sense of how satisfactory a description of the economy it provides, at least for some relevant dimensions. The facts with which the model is confronted below have direct implications for the counterfactual experiments aimed at quantifying the importance of labour reallocation to aggregate volatility.

\subsubsection{Aggregate volatility and co-movements}

The model is calibrated to match labour composition changes: indeed Figure 2 shows a good match with the empirical shares of market hours by sex, age and education.
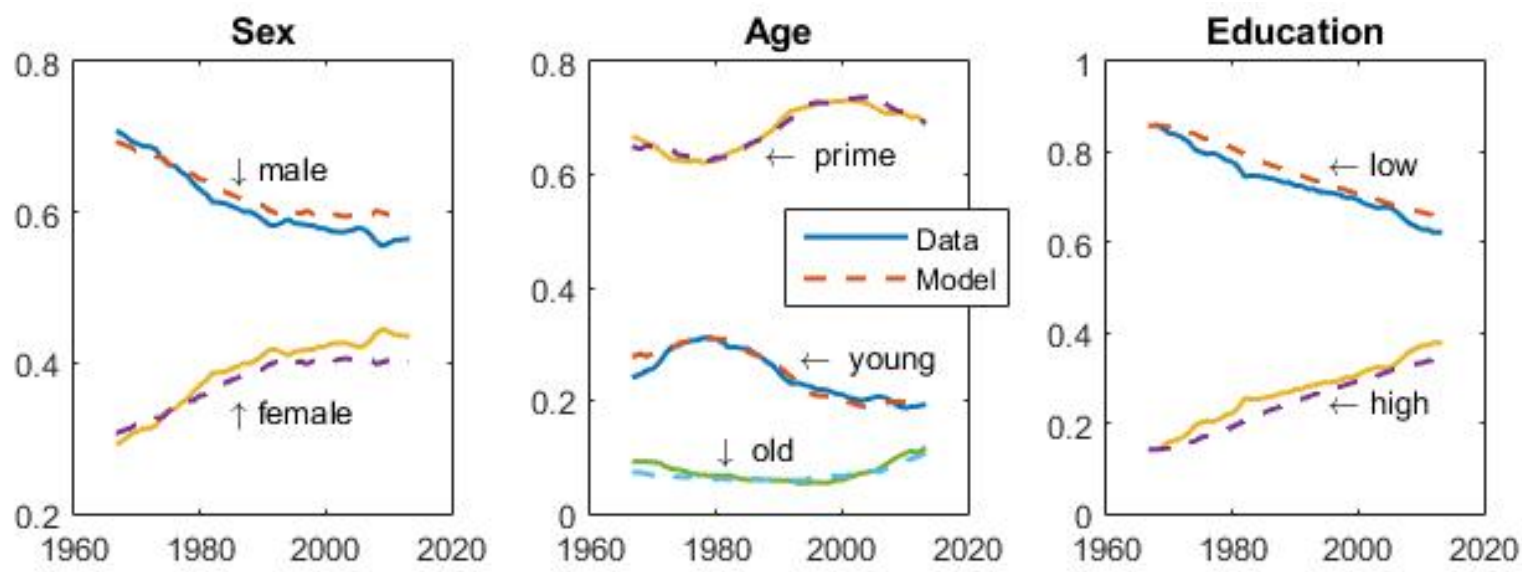

Figure 2: Data vs model share of total market hours

Since the model is restricted through demographic changes and most of the shocks are identified through disaggregated labour data, it is interesting to see whether simulating the model with the identified shocks- it replicates the changes in volatility, as well as the typical moments used to test RBC models.

As before, the model and data are HP-filtered. The standard deviations of output over the whole sample (67-13) is 1.10 in the model and 1.48 in the data. So the model accounts for $74 \%$ of total volatility, more than what is typically accounted for by RBC models: see for instance Prescott (1986). The standard deviation of total hours is $36 \%$ that of output as reported in Table 11: although much lower than in the data, this is an improvement to typical business cycle models given that the average elasticity is 1.1, see Ríos-Rull et al. (2012). A feature that contributes to this higher volatility 
is that the model distinguishes between TFP and labour augmenting shocks, which induce shifts in the labour demands of each group. Furthermore, the estimation of these shocks turns out to be less persistent than the Solow residual of an aggregate CD function (see table 9). The lower the persistence of shocks is, the lower the offsetting wealth effects they induce and the greater the labour response.

Table 11: Standard deviations relative to output and correlations

\begin{tabular}{lcccc}
\hline & \multicolumn{2}{c}{ Standard deviations } & \multicolumn{2}{c}{ Correlations with output } \\
\hline \hline & Data & Model & Data & Model \\
\hline \hline Output & 1 & 1 & 1 & 1 \\
Consumption & 0.82 & 0.63 & 0.91 & 0.32 \\
Investment & 4.57 & 4.11 & 0.93 & 0.87 \\
Hours & 1.12 & 0.36 & 0.71 & 0.89 \\
\hline
\end{tabular}

The model also predicts a volatility slow down between the first and second subsamples $(67-84$ vs $85-07)$ of $(1.49-0.87) / 1.49$ or $42 \%$ : quite close to the $50 \%$ decline documented in the literature, see for instance Arias et al. (2007).

Table 11 reports standard deviations and correlations with output of consumption, investment and total hours. Consistently with national income data (and in line with other RBC models), this model predicts that while consumption is less volatile than output, investment is much more volatile. These statistics remained fairly stable over the whole sample and cannot be held responsible for the changes in aggregate volatility. See for instance Arias et al. (2007).

\subsubsection{Wages, labour share and the employment-productivity puzzle}

As a by product, this model reconciles the employment-productivity puzzle - the nearzero correlation between hours and labour productivity - which lies at the root of an important critique to the RBC model which predicts a high positive correlation. See Galí (1999). In this model, the correlation of HP-filtered labour productivity (output over total hours) and total hours is 0.11. As explained in Section 3.3, this result relies on the distinction between labour-specific and TFP shocks. Figure 3 plots the time series of the labour shocks $z$ and the TFP shock defined as $A^{\frac{1}{\theta}} \cdot{ }^{41}$

\footnotetext{
${ }^{41}$ Since $\theta$ is negative, an increase in $A$ has a negative effect on output as is obvious from Equation (4). For this reason, TFP is defined as $A^{\frac{1}{\theta}}$ which has a positive impact on output.
} 

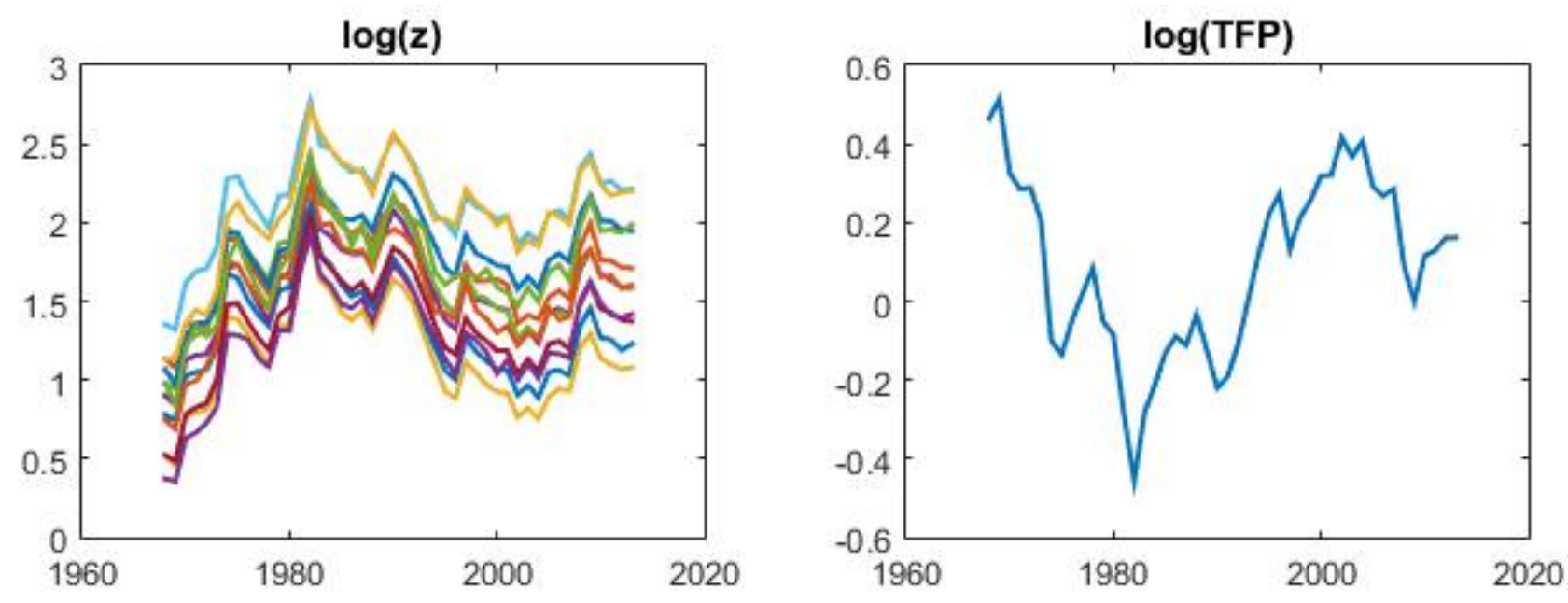

Figure 3: TFP and labour productivity by group.

The wedge between the marginal productivity of labour and output is also reflected in the labour share and wages: the fit with the empirical labour share, shown in Figure 4 last panel, shows a notable improvement to the constant labour share predicted with the benchmark CD technology. The Figure also shows actual versus predicted hourly wages by sex, age and education. In particular, despite the fact that female and highly educated labour supply increases over time, the model predicts a falling gender wage gap and an increasing education wage premium from 1979-1980 as documented, for instance by Card and DiNardo (2002) and Krusell et al. (2000). The reason is that the labour augmenting productivity processes specific to each group are identified through the wage equations (wage equal to marginal productivity for each group) taking into account the increase in female and highly educated hours. So, to the extent that the model generates the right hours and capital time series, it also predicts the right wages. 

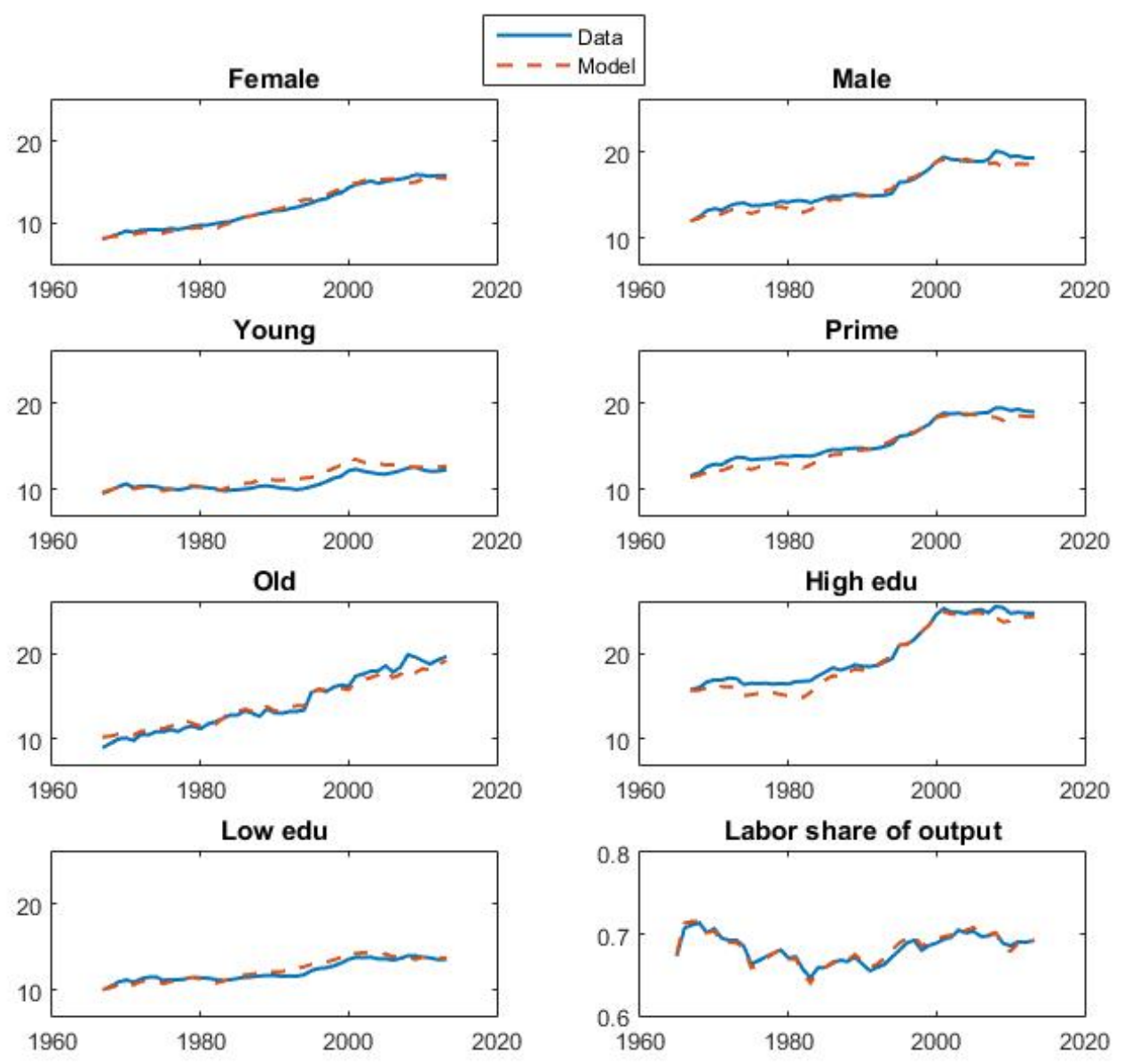

Figure 4: Wages per hour by group and labour share of output.

Appendix B offers an analytical illustration of how labour marginal productivities are affected by the shocks.

\subsubsection{Trends in labour elasticities}

It is also interesting to see whether the model predicts how hours and wages volatilities have evolved over time. Figure 5 shows these trends in the data and in the model. Besides matching relative volatilities on average, the figure also shows that the model predicts the time path by gender, age (prime over young and old) and education for both hours and wages. The path for this ratio in volatilities is roughly stable over time for gender and age and increasing for education (i.e. highly educated workers are becoming more volatile). This result suggests that the model gives a good account of how group specific volatility changes as a function of demographic change. 

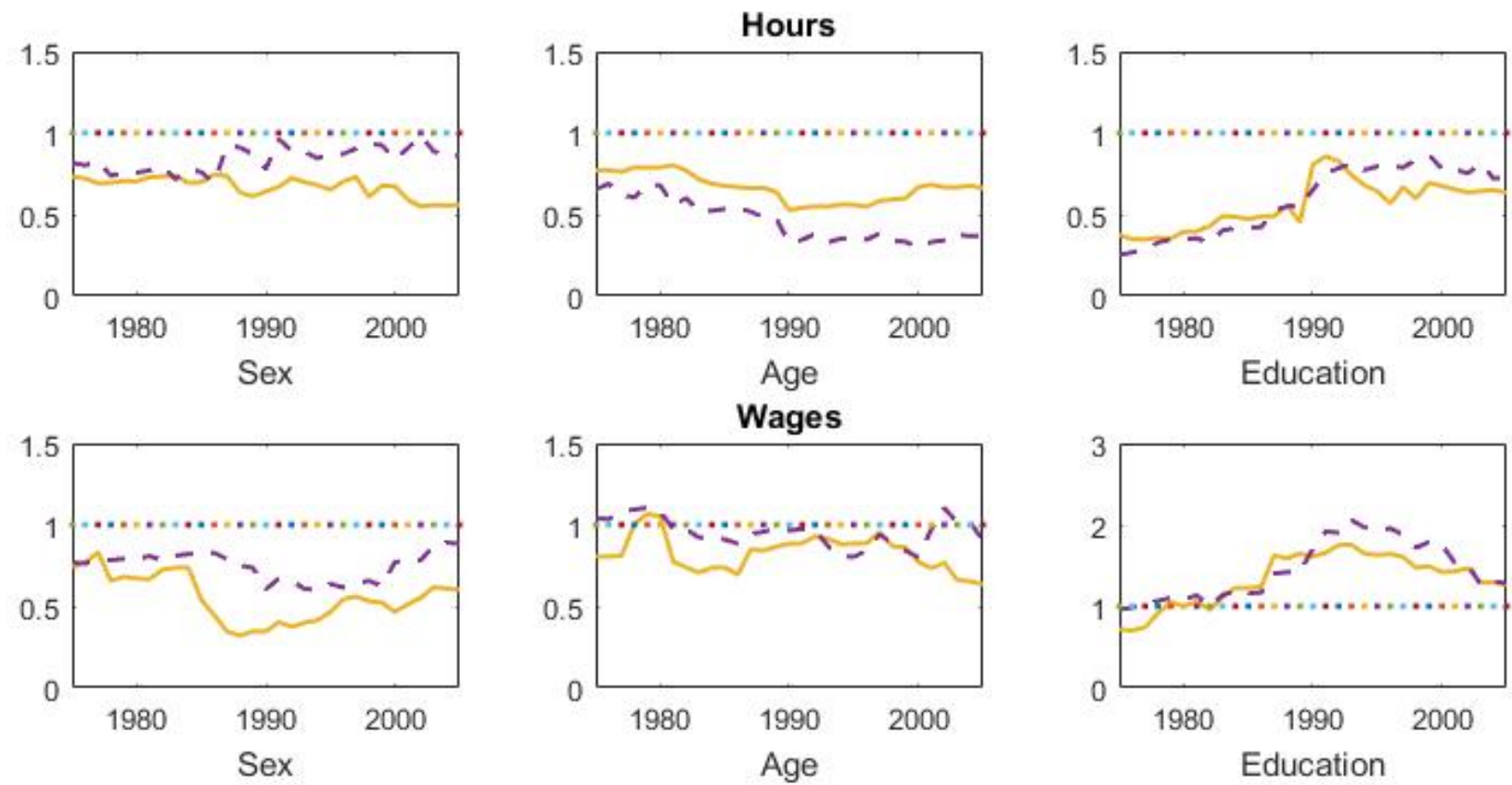

Figure 5: Hours and Wages volatility ratio by sex, age and education.

Notes: Dashed lines are model simulated data. The first row shows the ratio (female over male; prime over young and old; high over low education) of the standard deviation of HP-filtered total hours. The second row shows the same statistic for wages per hour weighted by hours by group. In each $t$, it is plotted the ratio of the standard deviations over a period of 15 years centered at year $t$.

The model's ability to replicate relative hours volatility by sex relies on the utility function, which implies that as women's labour input increases over time, their Frisch elasticities of labour supply declines (Equation (11)). This role of declining Frisch elasticities can be appreciated by observing Figure 6 which shows that with an alternative utility function with constant Frisch elasticties the volatility of female hours is increasing relative to that of men. Instead, declining female elasticities neutralize this upward trend in relative hours volatilities. ${ }^{42}$

\footnotetext{
${ }^{42}$ Time varying elasticities play a negligible role for the path of relative hours volatility by age and education; intuitively this is because both in the model and in the data, the largest change in labour per worker (and thereby labour supply elasticity) characterizes women while changes for males, age and education groups are more modest.
} 


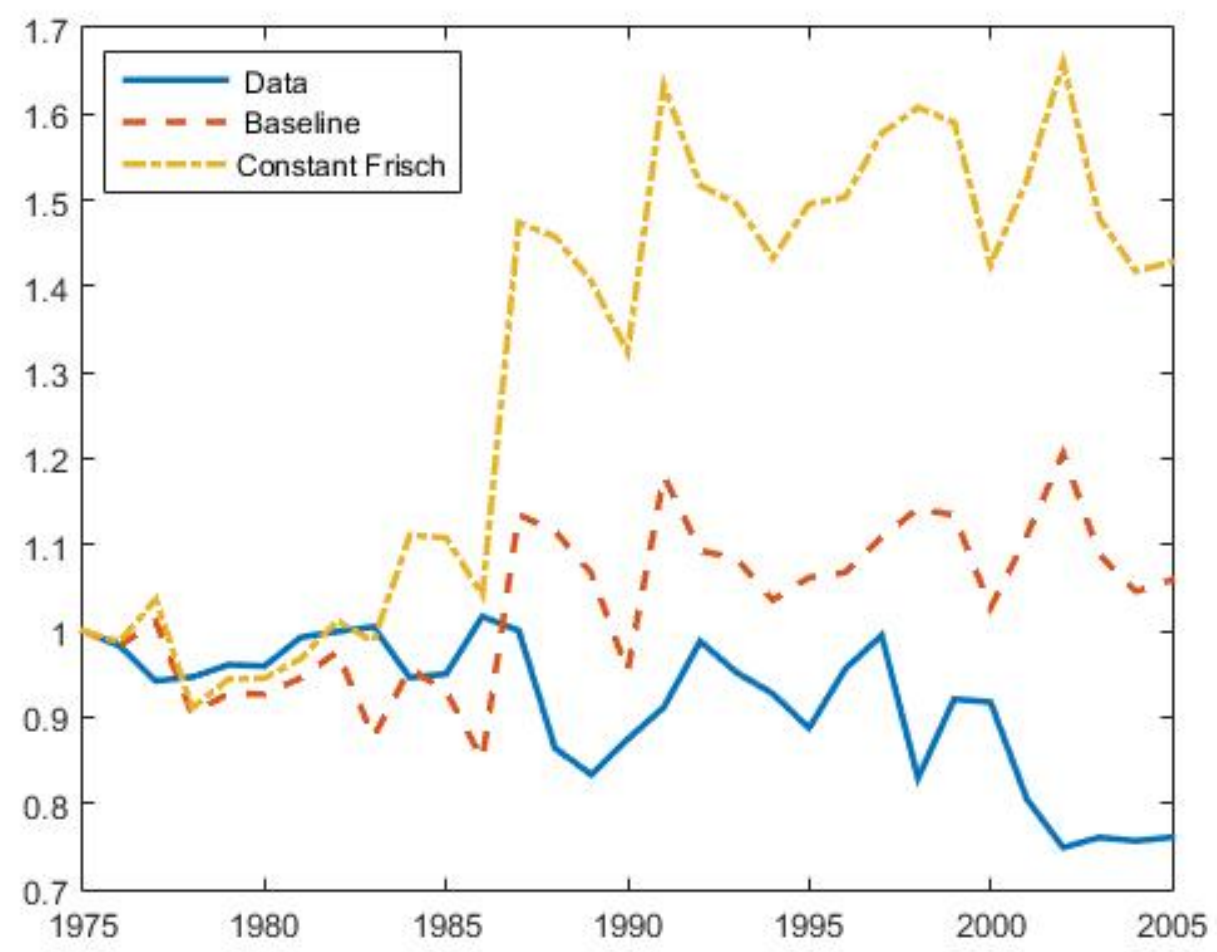

Figure 6: Comparing relative hours volatility between men and women with utility function with constant Frisch elasticity of labour supply.

Note: Time series are normalized to one at the beginning of the sample to ease comparison.

As mentioned, this decline in female labour supply elasticities is consistent with the findings of Heim (2007) and Blau and Kahn (2007). These papers called for an explanation of this fact. Through a decomposition exercise, Heim (2007) and Bargain et al. (2012) find that the decline is not accounted for by demographics in the sense that the decline in elasticities occurred for all female sub-groups rather than because of the change in the demographic composition, holding sub-group elasticities constant. My model confirms their finding that elasticity declines for all women's sub-groups; that notwithstanding, the model suggests that the elasticity decline was indeed due to demographics through its effect on labour input and its implication on the labour supply Frisch elasticity.

It should be noted that in this model female labour trends come from each woman working more hours. Instead, part of the increase in female total hours is due to participation decisions. This is a weakness because the elasticity in Equation (11) only involves the intensive margin. For instance, distinguishing between an intensive and 
an extensive margin would affect results if they behaved differently. However, tables 4 and 6 show that at least qualitatively, the trends in employment over population by gender, age, and education evolved similarly to hours per worker. Furthermore, column 3 in these tables show that both hours per worker and employment over population by women, prime age and the highly educated are less volatile than their respective counterparts (males, other age groups and workers with lower education). Finally, the last column in the two tables show similar patterns in the volatility decline in the Great Moderation period. As suggested by Heim (2007) and Blau and Kahn (2007), a possible intuition for a negative relationship between labour supply and its elasticity, not just at the intensive, but also at more extensive margins is that as more people participate, the number of people with reservation wage close to their market wage gets smaller and the participation elasticity will be small.

Furthermore, Section 2 finds that the most important distinction is between population margins - which characterized the changes by age and education- and the other two (employment and hours) which mattered for gender. The model merges employment and hours, but the population margin is kept separated from the other two.

While reassuring, this evidence does not mean that distinguishing between employment and hours would not matter. Indeed the drop in female total hours' elasticity between 1980 and 2000 is one quarter in the model, which is lower than the one half drop estimated by Blau and Kahn (2007): this suggests that the model gives a conservative estimate of the overall effects this elasticity channel has on aggregate volatility.

Finally, with the adopted production function, compositional changes also affect labour demand elasticities: as shown in Appendix B, the larger the labour input of one group, the lower the elasticity of the labour demand of that group to its labour shock and the more sensitive the labour demands of the other groups. Arguably, this is an interesting channel for the sake of this study. For instance, this model abstracts from the fact that the service sector, which is less volatile than other sectors, is female intense and has grown throughout the sample. Had female labour not increased, perhaps more men would have entered that sector reducing average male hours volatility. In the model, had female labour supply not increased, men would make a larger share of hours and their labour demand would respond less to their shocks. This is as if some men would have entered less volatile sectors. This mechanism, however, has small quantitative implications. Similarly, Blanchard and Simon (2001) and McConnell and Perez-Quiros (2000) find that sectorial shifts do not explain aggregate volatility. 
To summarize this section so far, the model is broadly consistent with a set of facts at the aggregate and at the group level. Even though the model inevitably lacks some important aspects of reality, it explains the evolution of the variables which are likely to matter for the questions of this paper. Next I rely on the model to predict how the agents would have responded in the counterfactual experiments.

\subsection{Counterfactual experiments}

\subsubsection{Removing all trends}

The counterfactual experiment consists of changing the trends in the amount of housework $\tilde{h}_{g, e}$, the birth rate dynamics $p_{0}$ and the education shares of the population- $q^{m}$ and $q^{f}$-while maintaining the shocks $A$ and $Z$ as in the baseline.

The initial population distribution is the steady state one implied by the steady state levels of $p_{0}, q^{m}$ and $q^{f}$. In order to construct the counterfactual with trend-less hours' shares by sex, the time cost $\tilde{h}_{g, e}$ has to be increasing over time for women, i.e. start below steady state: equal to $-0.5 \%$ of total time for women with low education and $-11 \%$ for highly educated women. Increasing time costs contrast the fact that female wages are fast increasing, especially for the highly educated.

Initial individual asset holdings are constructed in the same way as in the baseline simulation as detailed in Section 4.5: they are set equal to 0.85 times the assets obtained by solving for a steady state taking as given the initial demographic distribution.

Figure 7 shows market hours shares by gender, age and education in the counterfactual and original simulations: as can be seen, counterfactual hours are essentially trend-less. ${ }^{43}$ Table 12 contains the standard deviation of HP-filtered output and market hours during the sub-samples of interest: the period before the Great Moderation 1967-1984, and the period of the Great Moderation: 1985-2007. It is also instructive to focus on the initial 10 periods of especially high volatility, 1967-1976 (column 1), and the last part of the sample: 2000-2013 (last column).

\footnotetext{
${ }^{43}$ Small low frequency movements are still notable in hours shares by sex. This is because hours trends by sex are fully determined by endogenous labour supply decisions as opposed to trends by education and age, which come mainly from exogenous birth rates. As a result, it is not possible to make hours by sex fully constant simply with a deterministic AR1 time cost. However, non reported simulations confirm that the results reported below are robust to small changes in these trends.
} 

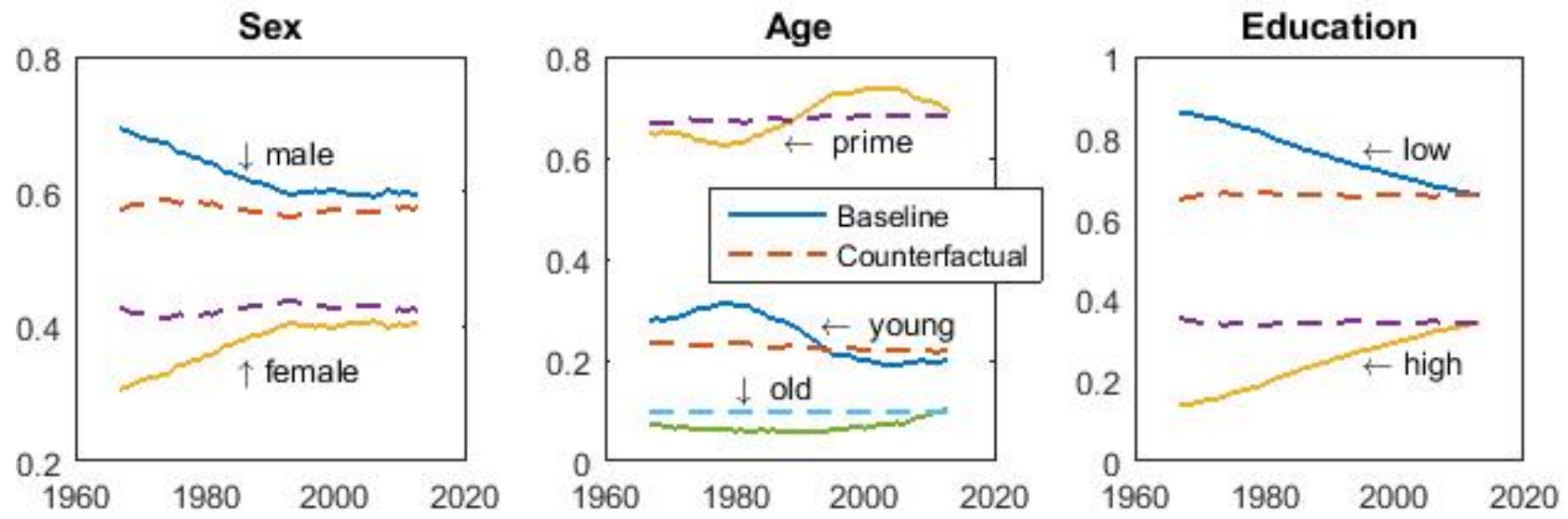

Figure 7: Shares of hours, original versus counterfactual simulation

Table 12: Standard deviation of HP-filtered output and hours over time

\begin{tabular}{l|cccc}
\hline & $67-76$ & $67-84$ & $85-07$ & $00-13$ \\
\hline Baseline simulation & 1.71 & Output & 0.92 \\
Counterfactual simulation & 1.36 & 1.49 & 0.87 & 0.92 \\
\hline & \multicolumn{4}{|c}{ Market Hours } \\
\hline Baseline simulation & 0.66 & 0.56 & 0.88 & 0.21 \\
Counterfactual simulation & 0.55 & 0.49 & 0.20 & 0.22 \\
\hline
\end{tabular}

As can be deduced from the first two rows in the table, output volatility in the first turbulent 10 years of the sample is $\log (1.76)-\log (1.36)$, or approximately $23 \%$ lower in the counterfactual than in the baseline, the discrepancy is $18 \%$ until 1984. Thus, in the absence of these trends, volatility is much lower in the first sample, when volatility was very high. Instead, during the Great Moderation (85-07) counterfactual volatility is $2 \%$ higher and it converges to the baseline one in the last years of the sample (as is natural given that the labour composition also converges to the baseline toward the end of the sample). Thus in the counterfactual, output volatility is much more stable over time. The same holds for total hours as shown in the third and fourth rows.

To get a visual sense of how volatility is affected over time, Figure 8 shows the time trend of baseline and counterfactual cyclical volatility measured as a 3-year roll over standard deviation of filtered output. 


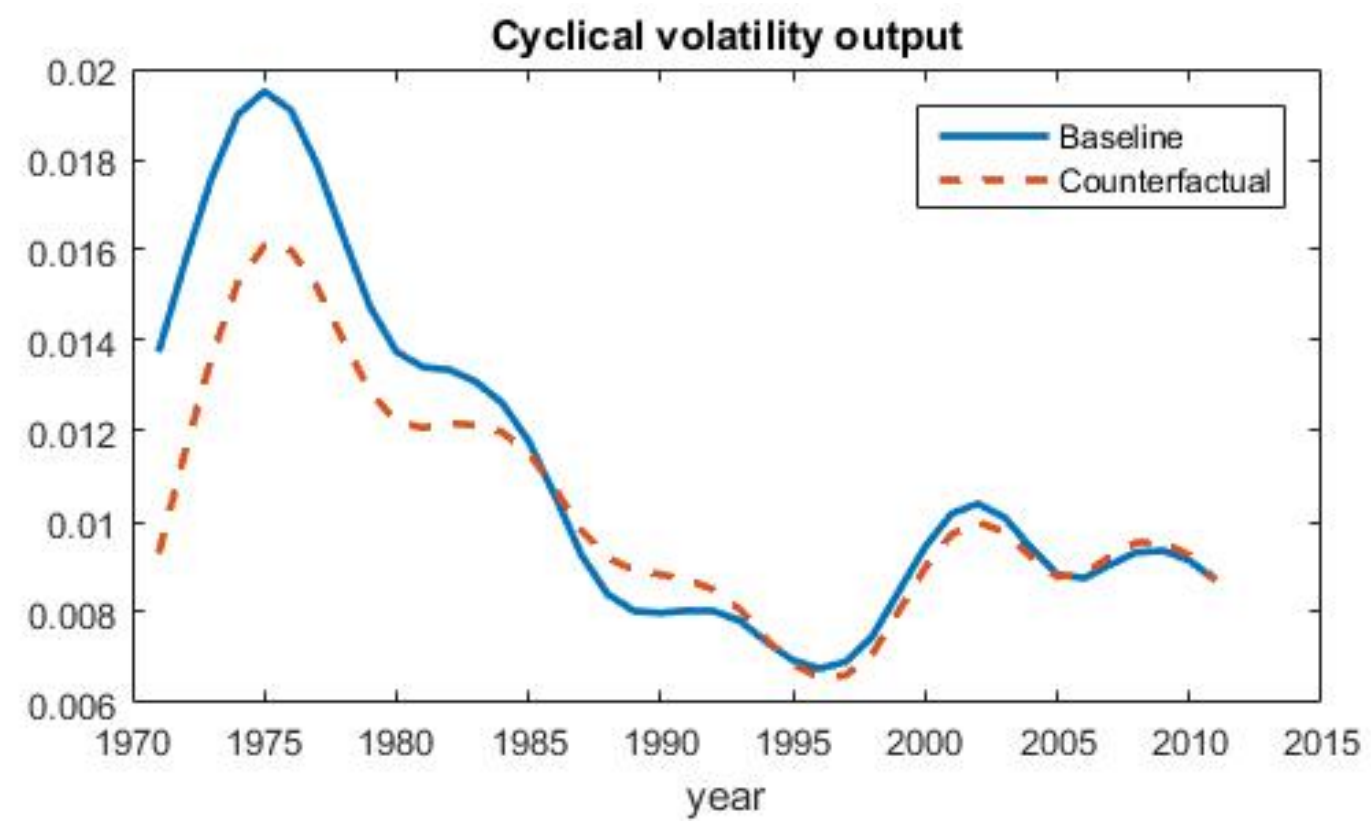

Figure 8: Output volatility, baseline versus counterfactual simulation with trend-less hours shares.

To get a concise statistic that quantifies the amount of the Great Moderation explained, I proceed as in section 5.2.1, comparing the standard deviations in the first sub-sample (1967-1984) and in the second one (1985-2007). Between the two subsamples, aggregate output volatility decreased by $(1.493-0.867) / 1.493$ or $41.9 \%$ in the baseline simulation. Had the shares remained stable as in the counterfactual, we would have observed a reduction in volatility of $(1.243-0.884) / 1.243$ or $28.9 \%$. Therefore, these demographic changes account for (41.9-28.9)/41.9 or $31 \%$ of the moderation in output. ${ }^{44}$ The same statistic for total hours is $12.3 \%$.

\subsubsection{Removing trends one by one}

What is the importance of each of the three factors? Table 13 includes the outcomes of counterfactual experiments where only one of the long-run trends is removed. ${ }^{45}$ The first column reports the share explained of the Great Moderation by each demographic trend: the numbers suggest that education trends are the most important for the Great

\footnotetext{
${ }^{44}$ What not accounted for by demographics is due to a lucky draw of small innovations or "good luck". This is similar to Arias et al. (2007) and Smets and Wouters (2007).

${ }^{45}$ Removing only trends by sex, hours shares by age and education are quite close to the baseline in Figure 7, while the shares by sex are close to the counterfactual ones. So there are small indirect effects. Indirect effects are also small when removing trends by age or education.
} 
Moderation in output, followed by trends in age and sex. Trends in age are the most important for the moderation in hours.

Table 13: Standard deviation ratios

\begin{tabular}{|c|c|c|c|c|c|}
\hline & $\begin{array}{c}\text { Great } \\
\text { Moderation }\end{array}$ & $\begin{array}{c}\text { Counterf.-Base } \\
\text { St.Dv. } 67-76\end{array}$ & $\begin{array}{c}\text { Counterf.-Base } \\
\text { St.Dv. } 67-84\end{array}$ & $\begin{array}{c}\text { Counterf.-Base } \\
\text { St.Dv. } 85-00\end{array}$ & $\begin{array}{c}\text { Counterf.-Base } \\
\text { St.Dv. 00-13 }\end{array}$ \\
\hline \multicolumn{6}{|c|}{ Output } \\
\hline$\overline{\text { All }}$ & 31.0 & -23.1 & $\begin{array}{l}-18.3 \\
\end{array}$ & 1.9 & -0.7 \\
\hline Sex & 3.3 & -4.0 & -3.4 & -0.7 & -0.7 \\
\hline Age & 4.4 & -0.8 & -0.4 & 2.7 & -1.8 \\
\hline Educ. & 25.4 & -17.5 & -13.6 & 3.3 & 1.8 \\
\hline \multicolumn{6}{|c|}{ Market Hours } \\
\hline$\overline{\text { All }}$ & 12.3 & -17.3 & -15.0 & 6.6 & 5.5 \\
\hline Sex & 2.1 & -5.4 & -5.3 & -1.4 & -2.2 \\
\hline Age & 7.9 & -6.6 & -6.3 & 3.1 & 11.4 \\
\hline Educ. & 4.3 & -7.2 & -7.4 & 0.7 & 1.0 \\
\hline
\end{tabular}

Notes: numbers are expressed in percentage terms. Great Moderation is a measure of the size of the volatility reduction that is accounted for by changes in the composition of labour. Counterfactual-Base St.Dv. measures the percentage difference between output volatility in the baseline and counterfactual simulation.

The statistic in column 1 , which is computed the same way as in the previous subsection, is concise and conventional in the literature. However, it is also instructive to see how volatility would have differed over time: columns $2-5$ report the volatility ratio relative to the original simulation for each of the sub-samples considered. Trends by education and sex matter primarily because they decrease counterfactual standard deviation in the initial most volatile period: for instance, if initial education composition was as in steady state, the standard deviation of filtered output would have been $\log (1.714)-\log (1.438)$ or $17.5 \%$ lower in the most turbulent initial decade of the sample. Age trends matter by reducing volatility in the first sub-sample, but especially by increasing counterfactual volatility in the Great Moderation period (fourth column): the standard deviation of counterfactual filtered output is about $3 \%$ higher without the disproportionately high share of prime age workers between 1985 and 2007. 


\subsubsection{Growth implications}

Finally, an interesting side result from this model is to measure the contribution for growth of these demographic trends.

The main factors contributing to growth in this model are the demographic trends, the path of the shocks, and the initial asset conditions. To disentangle the role of demographics for growth, I compare growth with and without demographic trends, holding the shocks and individual asset holdings as in the baseline.

In the absence of sex trends, average annual output growth between 1967 and 2013 would have been $1.28 \%$ as opposed to $1.53 \%$. Therefore $(1.53-1.28) / 1.53$ or $16.3 \%$ of the average growth rate is due to sex trends. Average output growth would have been $1.39 \%$ without age trends, and $1.27 \%$ without trends in education. Therefore $9.2 \%$ of the average growth rate is due to trends in age and $17 \%$ to education trends. Finally, removing sex, age and education trends jointly accounts for a staggering $39 \%$ of the average annual output growth. As mentioned in the introduction, the model ignores elements that could affect these results and more work should be done. However, the numbers appear conservative when compared to the literature, which provides estimates for each of these dimensions singularly: for instance Greenwood et al. (2005) find that the rise in female labour participation accounts for about $19 \%$ of growth between 1900 and 1980. Feyrer (2007) finds that changes in the labour composition by age explain almost 12\% of GDP growth between 1990 and 1995. The number for education is close to the $15 \%$ found by Goldin and Katz (2008) for human capital: they argue that their accounting exercise is likely to be an understatement because it misses indirect effects. See also Acemoglu and Autor (2012).

To the extent that the demographic composition is converging toward a stationary distribution, we should expect less growth in future.

\subsubsection{Sensitivity}

These results are quite robust to sensible changes in initial assets. As mentioned, initial individual asset holdings are as in the baseline. Intuitively, this reflects the hypothesis that demographics had no bearing on initial savings; this helps isolating the role of demographics from initial conditions. However, one could argue that demographics has some bearing on initial asset holdings: without the demographic transition, the model would start closer to its steady state, so also initial assets should be closer to steady state. Results are robust to this alternative: assuming that initial individual assets 
are 0.95 times their initial steady state rather than 0.85 , the average output growth is virtually unaffected. Initial assets have little impact also for aggregate volatility, for instance, with the latter initial conditions, sex, age and education trends account for $29.3 \%$ of the moderation in output rather than $31.0 \%$.

Initial conditions for TFP and labour shocks are identified from the data. Nevertheless it is instructive to run a simulation with different initial conditions. I choose the steady state values implied by the AR1 processes estimated for $A$ and $Z$. I keep the innovations I have identified from the estimation. Perhaps not surprisingly, the most notable fact is that output growth is now much lower: the average growth is 1.32 rather than 1.53. Interestingly, the business cycle implications of the model are essentially unchanged: for instance, the Great Moderation in output is of $42 \%$, as with the baseline initial conditions.

Conclusions are robust to changes in the parameter values concerning the complementarity between capital and labour in the production function, the average elasticity of labour supply (where values ranging between 1 and 1.5 have been considered) and changing the age classes (moving the young-to-prime age threshold from 30 to 34 and the old threshold from 59 to 54).

\section{Conclusion}

This paper documents changes in the composition of the labour force by gender, age and education and finds that they account for a significant portion of the change in aggregate volatility over the past half century. In particular, the paper finds that two key trends are increasing shares of college educated workers, and to a lower, yet significant degree, the rising female labour force participation. The paper also confirms that the changing shares of young and prime age workers had a relevant role. The intuition for these causal effects is that there are systematic differences in the sensitivity to the business cycle of labour market variables partitioned by education and gender, as well as by age. These conclusions are consistently reached with a reduced form methodology and with a more structural analysis.

Another achievement of the model is to measure the contribution to growth of these demographic trends. Intuitively, the increase in female labour and relatively more productive and hard working prime age and highly educated workers, contributed to the growth observed in the past half century: these trends account for almost $40 \%$ of 
the average output growth in the last 50 years. An important caveat is that in the model the long run demographic trends are due to exogenous causes but in the data they may be partly a byproduct of growth. Yet the estimates on the growth effects of demographic are conservative relative to existing estimates.

One challenge has been to find a solution method for this large model which guarantees sufficient precision over the dramatic demographic transition path that has characterized the last 50 years. This has been done by developing a technique that can be applied to a wide range of dynamic stochastic general equilibrium models, which essentially consists of applying perturbation methods at many points along the equilibrium path. The method is described in detail in Mennuni and Stepanchuk (2016).

Finally, it is worth mentioning that while this paper highlights positive implications of demographic change, the findings may matter for a variety of public debates that affect labour supply and its composition, ranging from tax, welfare, and pension reforms, to the regulation of institutional features of labour markets. Besides the policy implications, since demographic trends are fairly predictable, the uncovered implications on volatility and growth may help improve our forecasts.

\section{References}

Abraham, K. G., Shimer, R., 2001. Changes in Unemployment Duration and Labor-Force Attachment. Russell Sage Foundation, pp. 367-420.

Acemoglu, D., Autor, D., June 2012. What does human capital do? A review of Goldin and Katz's Race between Education and Technology. Journal of Economic Literature 50 (2).

Arias, A., Hansen, G. D., Ohanian, L. E., July 2007. Why have business cycle fluctuations become less volatile? Economic Theory 32 (1), 43-58.

Attanasio, O., Low, H., Sanchez-Marcos, V., 2008. Explaining changes in female labor supply in a life-cycle model. American Economic Review 98 (4).

Bargain, O., Orsini, K., Peichl, A., Jul. 2012. Comparing labor supply elasticities in europe and the us: New results. IZA Discussion Papers 6735, Institute for the Study of Labor (IZA).

Becker, G. S., Mulligan, C. B., August 1997. The Endogenous Determination of Time Preference. The Quarterly Journal of Economics 112 (3), 729-58. 
Blanchard, O., Simon, J., 2001. The long and large decline in U.S. output volatility. Brookings Papers on Economic Activity 32 (1), 135-174.

Blau, F. D., Kahn, L. M., 2007. Changes in the labor supply behavior of married women: 1980-2000. Journal of Labor Economics 25, 393-438.

Card, D., DiNardo, J. E., October 2002. Skill-Biased Technological Change and Rising Wage Inequality: Some Problems and Puzzles. Journal of Labor Economics 20 (4), 733-783.

Castro, R., Coen-Pirani, D., 02 2008. Why have aggregate skilled hours become so cyclical since the mid-1980s? International Economic Review 49 (1), 135-185.

Choi, S., Ríos-Rull, J.-V., 2009. Understanding the dynamics of the labor share: the role of non-competitive factor prices. Annales d'Economie et de Statistique (95-96), 251-277.

Clark, K. B., Summers, L., 1981. Demographic differences in cyclical employment variation. Journal of Human Resources 16.

Doepke, M., Tertilt, M., 2016. Families in macroeconomics. Handbook of Macroeconomics 2, $1789-1891$.

Erosa, A., Fuster, L., Kambourov, G., May 2015. Towards a micro-founded theory of aggregate labor supply. Working papers, IMDEA.

Feyrer, J., February 2007. Demographics and Productivity. The Review of Economics and Statistics 89 (1), 100-109.

Galí, J., March 1999. Technology, employment, and the business cycle: Do technology shocks explain aggregate fluctuations? American Economic Review 89 (1), 249-271.

Goldin, C., May 2006. The Quiet Revolution That Transformed Women's Employment, Education, and Family. American Economic Review 96 (2), 1-21.

Goldin, C., Katz, L. (Eds.), 2008. The Race between Education and Technology. Cambridge, MA: The Belknap Press of Harvard University Press.

Gomme, P., Rogerson, R., Rupert, P., Wright, R., 2005. The business cycle and the life cycle. In: NBER Macroeconomics Annual 2004, Volume 19. NBER Chapters. National Bureau of Economic Research, Inc, pp. 415-592.

Greenwood, J., Seshadri, A., Yorukoglu, M., 01 2005. Engines of liberation. Review of Economic Studies 72 (1), 109-133. 
Hansen, A. H., 1939. Economic progress and declining population growth. The American Economic Review 29 (1), 1-15.

Heathcote, J., Storesletten, K., Violante, G. L., 08 2010. The Macroeconomic Implications of Rising Wage Inequality in the United States. Journal of Political Economy 118 (4), $681-722$.

Heim, B. T., 2007. The incredible shrinking elasticities: Married female labor supply, 19782002. Journal of Human Resources 42 (4), 881-918.

Hoynes, H., Miller, D. L., Schaller, J., Summer 2012. Who Suffers during Recessions? Journal of Economic Perspectives 26 (3), 27-48.

Iseringghausen, M., Vierke, H., 2018. What drives output volatility? the role of demographics and government size revisited. European Economy Discussion paper 075.

Jaimovich, N., Pruitt, S., Siu, H. E., 2013. The demand for youth: Implications for the hours volatility puzzle. The American Economic Review 5 (103), 3022-3044.

Jaimovich, N., Siu, H. E., June 2009. The Young, the Old, and the Restless: Demographics and Business Cycle Volatility. American Economic Review 99 (3), 804-26.

Janiak, A., Monteiro, P. S., 2016. Towards a quantitative theory of automatic stabilizers: the role of demographics. Journal of Monetary Economics 78(C), 35-49.

Katz, L. F., Autor, D. H., October 1999. Changes in the wage structure and earnings inequality. Vol. 3 of Handbook of Labor Economics. Elsevier, Ch. 26, pp. 1463-1555.

Katz, L. F., Freeman, R., 1994. Rising wage inequality: The United States vs. Other Advanced Countries. Russell Sage Foundation for NBER, NY, pp. 29-62.

Katz, L. F., Murphy, K. M., 1992. Changes in Relative Wages, 1963-1987: Supply and Demand Factors. The Quarterly Journal of Economics 107 (1), 35-78.

Keane, M. P., 2011. Labor supply and taxes: A survey. Journal of Economic Literature 49 (4), 961-1075.

Kim, C.-J., Nelson, C., November 1999. Has the U.S. economy become more stable? A Bayesian approach based on a Markov-switching model of the business cycle. The Review of Economics and Statistics 81 (4), 608-616. 
King, M., Ruggles, S., Alexander, J., Flood, S., Genadek, K., Schroeder, M., Trampe, B., Vick, R., 2010. Integrated public use microdata series, current population survey: Version 3.0. Minneapolis: University of Minnesota.

Krusell, P., Ohanian, L. E., Rios-Rull, J.-V., Violante, G. L., September 2000. Capital-skill complementarity and inequality: A macroeconomic analysis. Econometrica 68 (5), 10291054.

Leon-Ledesma, M. A., McAdam, P., Willman, A., September 2010. Identifying the elasticity of substitution with biased technical change. American Economic Review 100 (4), 1330-57.

Ljungqvist, L., Sargent, T., May 2011. A labor supply elasticity accord? American Economic Review Papers and Proceedings 101 (3), 487-491.

Lugauer, S., November 2012a. Demographic Change And The Great Moderation In An Overlapping Generations Model With Matching Frictions. Macroeconomic Dynamics 16 (05), 706-731.

Lugauer, S., November 2012b. Estimating the Effect of the Age Distribution on Cyclical Output Volatility Across the United States. The Review of Economics and Statistics 94 (4), 896-902.

Lugauer, S., 2012c. The supply of skills in the labor force and aggregate output volatility. Research in Economics 66(3), 246-262.

Lugauer, S., Redmond, M., 2012. The age distribution and business cycle volatility: International evidence. Economics Letters 117 (3), 694-696.

McConnell, M., Perez-Quiros, G., December 2000. Output fluctuations in the United States: What has changed since the early 1980?s? American Economic Review 90 (5), 1464-1476.

Mennuni, A., Dec. 2013. Labor force composition and aggregate fluctuations. Discussion Paper Series in economics And Econometrics 1302, University of Southampton.

Mennuni, A., Stepanchuk, S., 2016. Dynamic perturbation. Manuscript.

Prescott, E. C., 1986. Theory ahead of business cycle measurement. Quarterly Review 102 (Fall), 9-22.

Prescott, E. C., Rogerson, R., Wallenius, J., January 2009. Lifetime aggregate labor supply with endogenous workweek length. Review of Economic Dynamics 12 (1), 23-36. 
Ravn, M. O., Uhlig, H., 2002. On adjusting the Hodrick-Prescott filter for the frequency of observations. The Review of Economics and Statistics 84 (2), 371-375.

Reichling, F., Whalen, C., Oct. 2012. Review of estimates of the frisch elasticity of labor supply. CBO Working Papers 18501, Congressional Budget Office.

Ríos-Rull, J.-V., July 1996. Life-Cycle Economies and Aggregate Fluctuations. Review of Economic Studies 63 (3), 465-89.

Ríos-Rull, J.-V., 2001. Population changes and capital accumulation: The aging of the baby boom. The B.E. Journal of Macroeconomics (1), 7.

Ríos-Rull, J.-V., Schorfheide, F., Fuentes-Albero, C., Kryshko, M., Santaeulalia-Llopis, R., 2012. Methods versus substance: Measuring the effects of technology shocks. Journal of Monetary Economics 59 (8), 826 - 846.

Smets, F., Wouters, R., June 2007. Shocks and frictions in U.S. business cycles: A Bayesian DSGE approach. American Economic Review 97 (3), 586-606.

Stock, J. H., Watson, M. W., 2003. Has the business cycle changed and why? In: NBER Macroeconomics Annual 2002, Volume 17. NBER Chapters. National Bureau of Economic Research, Inc, pp. 159-230.

Summers, L., 2013. Why stagnation might prove to be the new normal. The Financial Times. 


\section{Appendixes}

\section{A Equilibrium}

Definition 1 A recursive competitive equilibrium is composed of a value function for the agents $V(g, j, e, a ; \omega)$, consumption, assets and labour functions $c(g, j, e, a ; \omega)$, $a^{\prime}(g, j, e, a ; \omega)$, and $\ell(g, j, e, a ; \omega)$; a agents' distribution function $p^{\prime}(g, j, e ; \omega)$, aggregate capital $K$, output $Y$, labour inputs $n_{i}$ for all $i$ and their aggregation $L$. Pricing functions $r(\omega)$ and $w(g, j, e ; \omega)$ and a transition process for the aggregate state vector $\Pi\left(\omega^{\prime} \mid \omega\right)$ such that the following conditions are satisfied:

1. The decision rules for consumption, assets and labour $c, a^{\prime}, \ell$, and the value function $V$ solve the agents problem in 3.1 .

2. Capital and labour inputs satisfy equations (7) and (8).

3. Labour markets clear. i.e. equation (6) holds for all $i$.

4. The capital market clears: $K=\sum_{g} \sum_{j=1}^{J} \sum_{e} a(g, j, e) p^{\prime}(g, j, e ; \omega)$. Where $a(g, j, e)$ is the asset position by gender, age and education.

5. The goods market clears: $C+K^{\prime}-K(1-\delta)=Y$, where $C=\sum_{g} \sum_{j=1}^{J} \sum_{e} c(g, j, e, a ; \omega) p^{\prime}(g, j, e ; \omega)$, $K^{\prime}=\sum_{g} \sum_{j=1}^{J} \sum_{e} a^{\prime}(g, j, e, a ; \omega) p^{\prime}(g, j, e ; \omega)$, and $Y$ is given by the production function (4) with aggregate capital $K$, and $L$ defined by Equation (5).

6. $\Pi\left(\omega^{\prime} \mid \omega\right)$ is consistent with Sections 3.2 and 3.4, and with agents expectations and decision rules.

\section{B Labour demand sensitivity to shocks.}

I show next some analytical properties of the production function referred to in Sections 5.2.2 and 5.2.3.

For illustration purposes, I only consider men and women and abstract from the other groups. The marginal productivity of female labour is

$$
f_{\ell_{f}}=(1-\alpha) A^{\frac{1}{\theta}}\left(\alpha k^{\theta}+(1-\alpha)\left(z_{m} \ell_{m}+z_{f} \ell_{f}\right)^{\theta}\right)^{\frac{1}{\theta}-1}\left(z_{m} \ell_{m}+z_{f} \ell_{f}\right)^{\theta-1} z_{f} .
$$

It is then possible to construct the elasticity of labour demand to the shocks $A, z_{m}$ and $z_{f}$, holding labour and capital constant. These measure the shifts in the labour demand curve in response to the shocks.

$$
\varepsilon_{z_{f}} \equiv \frac{\partial f_{\ell_{f}}}{\partial z_{f}} \frac{z_{f}}{f_{\ell_{f}}}=\frac{(1-\theta) z_{f} \ell_{f}}{z_{m} \ell_{m}+z_{f} \ell_{f}}\left(\frac{(1-\alpha)\left(z_{m} \ell_{m}+z_{f} \ell_{f}\right)^{\theta}}{\left(\alpha k^{\theta}+(1-\alpha)\left(z_{m} \ell_{m}+z_{f} \ell_{f}\right)^{\theta}\right)}-1\right)+1
$$




$$
\begin{gathered}
\varepsilon_{z_{m}} \equiv \frac{\partial f_{\ell_{f}}}{\partial z_{m}} \frac{z_{m}}{f_{\ell_{f}}}=\frac{(1-\theta) z_{m} \ell_{m}}{z_{m} \ell_{m}+z_{f} \ell_{f}}\left(\frac{(1-\alpha)\left(z_{m} \ell_{m}+z_{f} \ell_{f}\right)^{\theta}}{\left(\alpha k^{\theta}+(1-\alpha)\left(z_{m} \ell_{m}+z_{f} \ell_{f}\right)^{\theta}\right)}-1\right) \\
\varepsilon_{A} \equiv \frac{\partial f_{\ell_{f}}}{\partial A} \frac{A}{f_{\ell_{f}}}=\frac{1}{\theta}
\end{gathered}
$$

From the last equation it is immediate that the elasticity of labour demand to $A$ is not affected by changes in female labour $l_{f}$. Figure 9 shows how the elasticities to $z_{f}$ and $z_{m}$, computed using Equations (14) - (16), change with $l_{f}$ given the calibration in the paper and steady state shocks, capital and male labour: first, the elasticity to $z_{f}$ decreases while that to $z_{m}$ increases; second, the elasticity to $z_{f}$ is larger and steeper in absolute value than that of $z_{m}$.
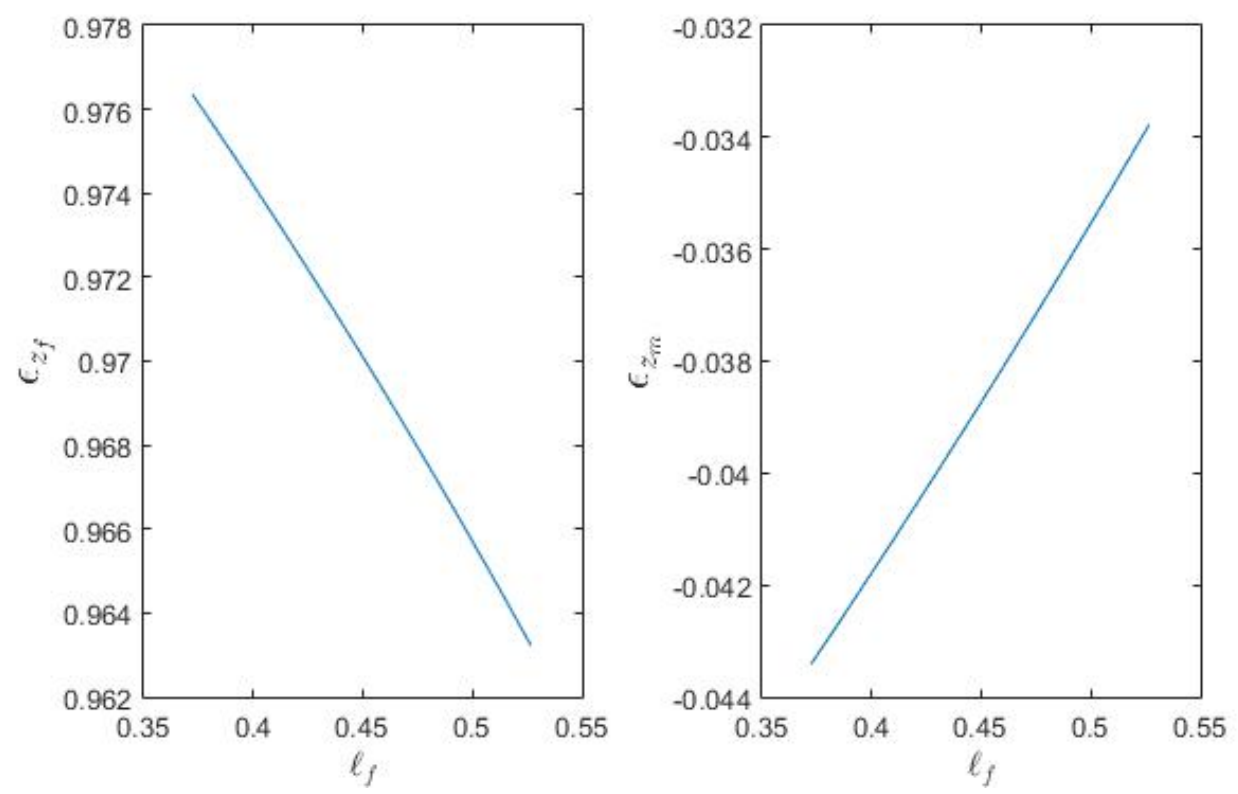

Figure 9: Elasticity of female labour demand to $z_{f}$ and $z_{m}$

These elasticities imply that the response to shocks decreases with $l_{f}$. To illustrate this, it is instructive to assume perfectly correlated shocks $z_{f}, z_{m}, A .{ }^{1}$ With constant elasticities, the labour demand shift to an impulse that increases the shocks $z_{f}, z_{m}, A$ by a proportion $\sigma$ is $^{2}$

$$
\frac{\Delta f_{\ell_{f}}}{f_{\ell_{f}}}=\varepsilon_{z_{f}} \sigma+\varepsilon_{z_{m}} \sigma+\varepsilon_{A} \sigma .
$$

\footnotetext{
${ }^{1}$ They are indeed positively correlated, I consider the empirical covariance structure later.

${ }^{2}$ The expression that follows comes from the fact that - holding capital and labour constant $\frac{\Delta f_{\ell_{f}}}{f_{\ell_{f}}} \simeq \frac{1}{f_{\ell_{f}}}\left(\frac{\partial f_{\ell_{f}}}{\partial z_{f}} \Delta z_{f}+\frac{\partial f_{\ell_{f}}}{\partial z_{m}} \Delta z_{m}+\frac{\partial f_{\ell_{f}}}{\partial A} \Delta A\right)$ where $\Delta z_{m}=\sigma z_{m}, \Delta z_{f}=\sigma z_{f}, \Delta A=\sigma A$. Here and below it is understood that $\Delta f_{\ell_{f}}$ measures the shift in the marginal productivity holding capital and labour constant i.e. a labour demand shift.
} 
So how does $\frac{\Delta f_{\ell_{f}}}{f_{\ell_{f}}}$ change with $l_{f}$ ?

$$
\frac{\partial \frac{\Delta f_{\ell_{f}}}{f_{\ell_{f}}}}{\partial \ell_{f}}=\frac{\partial \varepsilon_{z_{f}}}{\partial \ell_{f}} \sigma+\frac{\partial \varepsilon_{z_{m}}}{\partial \ell_{f}} \sigma .
$$

Since $\frac{\partial \varepsilon_{z_{f}}}{\partial \ell_{f}}<0, \frac{\partial \varepsilon_{z_{m}}}{\partial \ell_{f}}>0$ and $\left|\frac{\partial \varepsilon_{z_{f}}}{\partial \ell_{f}}\right|>\left|\frac{\partial \varepsilon_{z_{m}}}{\partial \ell_{f}}\right|$, it follows that $\frac{\partial \varepsilon_{z_{f}}}{\partial \ell_{f}}+\frac{\partial \varepsilon_{z_{m}}}{\partial \ell_{f}}<0$ so that $\frac{\Delta f_{\ell_{f}}}{f_{\ell_{f}}}$ is decreasing in $\ell_{f}$. Similarly, it is possible to see how demand shocks to male hours respond to the increase in $\ell_{f}$. Responses are qualitatively the opposite $\left(\frac{\Delta f_{\ell_{m}}}{f_{\ell_{f}}}\right.$ increasing in $\ell_{f}$ ).

More generally, it is possible to compute how the standard deviations of $\frac{\Delta f_{\ell_{f}}}{f_{\ell_{f}}}$ and $\frac{\Delta f_{\ell_{m}}}{f_{\ell_{f}}}$ move with $\ell_{f}$, taking into account the entire covariance matrix of the shocks $\hat{z} \equiv[z, A]$. For each of the 12 groups (e.g. female, young, with low education) the standard deviation can be approximated assuming constant elasticities as

$$
\operatorname{ST} . \operatorname{DEV}\left(\frac{\Delta f_{\ell}}{f_{\ell}}\right)=\left(\sum_{i, j} \frac{\partial f_{\ell}}{\partial \hat{z}_{i}} \frac{\hat{z}_{i}}{f_{\ell}} \frac{\partial f_{\ell}}{\partial \hat{z}_{j}} \frac{\hat{z}_{j}}{f_{\ell}} \sigma(i, j)\right)^{1 / 2}
$$

where $i, j$ index the shocks collected in $\hat{z}$ and $\sigma(i, j)$ is the covariance between $\hat{z}_{i}$ and $\hat{z}_{j}$. Equation (17) comes from the formula for the variance of a sum and stems from the fact that $\frac{\Delta f_{\ell}}{f_{\ell}} \simeq \sum_{i} \frac{\partial f_{\ell}}{\partial \hat{z}_{i}} \frac{\Delta \hat{z}_{i}}{f_{\ell}}$.

To get a sense of the average volatility of labour demand shifts for men and women, I compute the following average by sex

$$
\frac{\sum_{i} \operatorname{ST} . D E V\left(\frac{\Delta f_{\ell_{i}}}{f_{\ell_{i}}}\right) \ell_{i}}{\sum_{i} \ell_{i}}
$$

where $i$ either includes all groups of females or males.

With $\ell_{i}$ 's and elasticities computed using Equations (14)-(16) from the steady state where hours shares by sex are equal to the average between 67 and 84, the standard deviation of female labour demand shifts over that of men is 0.503 . With $\ell_{i}$ 's and elasticities computed with hours shares at the final steady state, the relative volatility is 0.492 . This corresponds to a drop of $2.2 \%$. The corresponding drop in wage volatility between the two simulations is $0.80 / 0.83-1$ or $3.6 \%$. So these elasticities account for about $60 \%$ the change in wage volatility due to the increase in female hours. ${ }^{3}$

The described mechanism, based on labour demand, comes from the adopted production function. This property holds for $\theta$ larger or smaller than zero, the Cobb-Douglas case. As explained in the paper, in the Cobb-Douglas case it is not possible to distinguish between TFP and labour shocks, but the result holds true if one approaches $\theta=0$ from the left or from the right.

\footnotetext{
${ }^{3}$ The remaining part may be due to a number of factors including the endogenous movement in capital, held constant in the calculation of these elasticities and the labour supply movements.
} 
While this analysis improves the understanding of the model, it should be noted that this mechanism has small bite in practice: the relative volatility of labour demand by sex only moves from 0.50 to 0.49 , so clearly the fact that the standard deviation of female wages is lower than for males has to do with the size of the shocks. In particular, the mechanism above is unlikely to have much propagation on the response of aggregate volatility to changing shares. Several unreported robustness checks confirm that the aggregate volatility effects of changing shares are quite robust to changes in relative volatilities of the magnitude implied by the labour demand elasticities. 